\title{
Áreas de recarga hídrica de la parte media-alta de las microcuencas Palo, Marín y San Rafaelito, San Carlos, Costa Rica
}

\author{
Harold Blanco Rojas \\ Universidad Estatal a Distancia, Sabanilla de Montes de Oca, San José, Costa Rica; harillob@gmail.com
}

Recibido 7-I-2010 Corregido 29-IV-2010 Aceptado 11-V-2010

\begin{abstract}
Water recharges areas on the highlands of the micro watersheds Palo, Marin and San Rafaelito, San Carlos, Costa Rica. The inappropriate land use inside the Water Recharge Areas (WRA) threatens groundwater resources. I determined all the locations with potential for groundwater recharge through soil water balance, to determinate the coefficients of soil texture $(\mathrm{kfc})$, slope $(\mathrm{Kp})$ and types of vegetal coverage $(\mathrm{Kv})$. A Geographic Information System (GIS) generated maps for soil texture, slope, plant cover and precipitation. The over-imposed maps identified 25 WRA and their potential evapotraspiration (PET), initial humidity (Sih), humidity retention of soil, apparent density ( $\rho \mathrm{a})$, basic infiltration of soil ( $\mathrm{fc}$ ), interception of the rain and depth of the roots that extract water. This was added to a soil water balance equation. In total, 25 WRA have an important potential aquifer recharge (Rp). This is largely due to the physical characteristics of the soil, which favor humidity retention and direct percolation. However, the WRA with little forest cover has little ability to store humidity and it is contribution is given through percolation, mainly during the rains. Forest areas stored more humidity and there is flow the whole year, even without precipitation. Rp in all areas tended to be moderate ( 1064 to $2073 \mathrm{~mm} /$ year), mainly because the real evapotraspiration (RET) generated some homogeneity in the Rp. More than 23 million $\mathrm{m}^{3}$ of water are recharged in the studied area annually.
\end{abstract}

\section{KEY WORDS}

Water resource, water recharge, aquifer, infiltration, water balance, groundwater.

\section{RESUMEN}

El uso de la tierra dentro de las Áreas de Recarga Hídrica (ARH), no es compatible con los fines de protección y conservación del recurso hídrico subterráneo. Para determinar cuáles son los sitios con mayor potencial de recarga de agua subterránea, se realizó un balance hídrico de suelos. Los datos generados responden a los coeficientes de las variables: textura del suelo $(\mathrm{kfc})$, pendiente $(\mathrm{Kp})$ y tipo de cobertura vegetal (Kv). Por medio de un Sistema de Información Geográfica (SIG), se generaron mapas digitales que representan la textura del suelo, la pendiente, el tipo de cobertura vegetal del suelo y la precipitación. Los mapas se superpusieron para identificar $25 \mathrm{ARH}$, para las cuales se determinó: evapotranspiración potencial (ETP), humedad inicial (Hsi), retención de humedad del suelo, densidad aparente (pa), infiltración básica del suelo (fc), intercepción de la lluvia y profundidad de las raíces extractoras de agua. La información generada para cada ARH, se ingresó a la ecuación general del balance. En las $25 \mathrm{ARH}$ se da una importante recarga potencial del acuífero (Rp), debido en gran medida a las características físicas del suelo, las cuales favorecen la retención de humedad y la percolación directa del agua hacia un posible acuífero existente en la zona. No obstante, las ARH con ausencia de cobertura boscosa, presentan una menor capacidad para almacenar humedad y su aporte se da debido a la percolación del agua, que en gran parte se presenta cuando ocurren las precipitaciones. En las ARH cubiertas por bosque, se presenta una mayor capacidad para almacenar humedad. Por consiguiente, tanto la retención de humedad como la percolación, hacen posible el flujo de agua superficial y subterránea a lo largo de todo el año, aun cuando no ocurren precipitaciones. Los resultados de Rp en todas las ARH tienden a ser moderadamente uniformes con valores que van desde los 1064 hasta los 2073mm/año, debido principalmente a que la evapotranspiración provocó cierta homogeneidad en la Rp. En general, en el área de estudio se recargan más de 23 millones de $\mathrm{m}^{3}$ de agua anualmente.

\section{PALABRAS CLAVE}

Recurso hídrico, recarga hídrica, acuífero, infiltración, balance hídrico, agua subterránea 
El marco legal e institucional en Costa Rica, respalda el deber civil y estatal de velar por la captación, tratamiento, distribución, protección y conservación del recurso hídrico. La Ley de Aguas 276 en su artículo 1, definió este recurso como bien de dominio público, respaldando el derecho de las personas de acceder al agua como un producto ambiental indispensable para la supervivencia (Asamblea legislativa 2004). Esta misma Ley, permite bajo concesión, que el agua como fuente de desarrollo sea utilizada para múltiples actividades productivas, entre ellas, el riego, la hidroenergía, y el desarrollo agropecuario. Además, en el artículo 17, se menciona la prioridad de abastecer a la población de agua para consumo, antes de destinar caudales de agua a otras actividades productivas. Para Calvo (1996), en los últimos años ha crecido la preocupación por el manejo adecuado del recurso hídrico y su persistencia depende de las medidas políticas, legales, administrativas y técnicas que se adopten. La institucionalidad y los civiles, fundamentados en la ciencia y la tecnología, deben velar y controlar la justa protección, conservación y distribución del recurso hídrico. Lo anterior se regula claramente en la Ley Forestal 7575, en su artículo 33, inciso d (Asamblea legislativa 1996).

Congruente con lo mencionado por Calvo (1996) en el párrafo anterior, el objetivo de esta investigación es identificar aquellas áreas donde es mayormente favorable la infiltración de agua superficial. La inexistencia de estudios relacionados con la protección del agua, la presencia de ASADAS, asociaciones ambientalistas y otros grupos organizados preocupados por la permanencia de este importante recurso, así como el apoyo técnico, legal y logístico que estas organizaciones deben recibir de parte de instituciones gubernamentales, crean un ambiente propicio para determinar y manejar adecuadamente las Áreas de Recarga Hídrica (ARH) en la zona.

Las microcuencas Palo, Marín y San Rafaelito se localizan en la falda noreste del Parque Nacional del Agua Juan Castro Blanco (PNAJCB), el cual es un punto importante de recarga hídrica que permite la emergencia de manantiales importantes en la parte media y baja de las mencionadas microcuencas (Guzmán 2004). El Instituto de Políticas para la Sostenibilidad (IPS), realizó un balance hídrico en la zona con el fin de generar información base para la implementación del Servicio Ambiental Hídrico (SAH) en cuatro cantones de la región. Este estudio reconoce que todo el flanco noroeste del PNAJCB, es una gran área de recarga hídrica, favorecida por la precipitación de tipo orográfica y por una geología de origen volcánico predominante en la zona (Barrantes \& Vega 2004). Aun así, en la zona no existe ningún estudio detallado que identifique las áreas más importantes de recarga hídrica y mucho menos se han propuesto acciones ágiles y pertinentes para su manejo.

El área de estudio comprende la mayor parte del territorio de la comunidad de San Juan. En esta comunidad, la distribución de agua para consumo humano se da mediante la Asociación Administradora de Acueducto Rural (ASADA). Igualmente, en la parte media de estas microcuencas, emergen manantiales que abastecen de agua potable a las comunidades de San Luís, El Quiosco, Monte Oreb y Linda Vista. Todas estas ASADAS, en su afán de proveer agua en cantidad y calidad, deben realizar una serie de acciones administrativas que favorezcan la conservación del recurso hídrico disponible para consumo. Entre los deberes de las ASADAS, la protección de las áreas importantes de recarga de los acuíferos, prevalece, ya que se debe garantizar el flujo y el aprovechamiento racional del agua a perpetuidad (AyA 2004). A la fecha, este deber no se ha cumplido, debido a que no se conocen los sitios prioritarios de recarga de los manantiales que actualmente se utilizan para abastecimiento poblacional (Ochoa 2007).

El área de estudio se caracteriza por presentar una reducida cobertura boscosa y una inminente amenaza por contaminación del agua debido al incremento desordenado e insostenible de la actividad bovina, agrícola, turística y demográfica. La plusvalía de las tierras, así como el clima agradable que impera en la zona, contribuyen con lo anterior. Estos hechos evidencian la necesidad de identificar las áreas donde es mayormente favorable la recarga hídrica, con el fin proteger los reservorios de agua subterránea y superficial en la zona.

Con la identificación de las ARH, se genera información novedosa que puede ser utilizada como insumo o complemento en la realización de otros estudios similares. Además, el estudio podría ser fuente de consulta ante el Plan Regulador y de Ordenamiento Territorial del Cantón de San Carlos. Los resultados del estudio pueden servir de base para la toma de decisiones y enfoque de los planes de acción, en asociaciones conservacionistas, empresas hidroeléctricas, ASADAS, Área de Conservación Arenal Huetar Norte (ACAHN) y Municipalidad de San Carlos. Igualmente, el estudio puede ser de consulta y utilidad para la aprobación o prohibición de ciertas actividades que atentan con el uso indebido de aquellas áreas favorables de recarga hídrica, contribuyendo así, a la planificación del crecimiento urbano y el desarrollo, tanto en el área de estudio, como en aquellas comunidades aledañas beneficiadas con el recurso hídrico. La aplicación práctica de la metodología utilizada y su relativo bajo costo, hacen posible la réplica de esta investigación por parte de organizaciones, comunidades u otros entes interesados en el manejo y conservación del recurso hídrico. 


\section{METODOLOGÍA}

A partir de un análisis de diferentes métodos (Balance Hídrico de Thornthwaite, Balance Hídrico de un Ecosistema de Holdridge, Método para Determinar la Recarga de Agua Subterránea (RAS), Metodología para la Determinación de Áreas de Recarga Hídrica Natural (DARHN) y el Cálculo de Recarga Potencial de Acuíferos mediante un Balance Hídrico de Suelos de Gunther Schosinsky), se concluyó que, debido a la amplitud del análisis y conclusiones que permite, los requerimientos de información que respaldan resultados más próximos a la realidad, así como a su reciente actualización y aplicación en Costa Rica, el método de Schosinsky es el más apto para desarrollar la presente investigación.

En la Zona Norte de Costa Rica, es la primera vez que se aplica este método y por tanto, la información que se generará podría ser novedosa y estaría disponible para ser comparada, validada o refutada por otras investigaciones que en este tema se lleven a cabo en la región. La toma de datos en el campo se dio en el periodo comprendido entre los meses de Enero y Marzo del año 2008.

A continuación se describe el "Cálculo de Recarga Potencial de Acuíferos mediante un Balance Hídrico de Suelos", que consiste en 15 pasos (Schosinsky 2006):

\section{Paso 1: Delimitación del área de estudio}

Después de definir el área de estudio, se delimitó la parte media-alta de las microcuencas Palo, Marín y San Rafaelito con un Sistema de Información Geográfica (SIG). En la delimitación del área de estudio se utilizó el mapa digital de las hojas cartográficas Aguas Zarcas № 3347 III y Quesada № 3346 IV (IGN 1986), así como la fotografía aérea Encarta-2005 № 485p0351 (CENAT 2005).

\section{Paso 2: Determinación de la distribución de las precipitaciones}

Mediante convenio con el Instituto Costarricense de Electricidad (ICE) y el Instituto Meteorológico Nacional (IMN), se tuvo acceso a información pluviométrica, entre el año 2003 y 2006, de 14 estaciones meteorológicas que se encuentran próximas al área de estudio. Las estaciones de interés fueron: Santa Clara, Florencia, La Marina, COOPELESCA, El Chato, Las Nubes, Río Segundo, San Vicente, Bajos del Toro, San Gerardo, Gorrión, Quebrada Pilas, Alto Palomo y Picada Palmira. La precipitación promedio mensual se calculó mediante la ecuación (1) (Gómez 2003):

$$
\begin{aligned}
& P=\left(P m_{1}+P m_{2}+P m_{3} \ldots .\right) / n \\
& \text { Donde: } \\
& P=\text { Precipitación promedio mensual } \\
& \mathrm{Pm}_{1}+\mathrm{Pm}_{2}+\mathrm{Pm}_{3} \ldots=\text { Suma de precipitaciones mensuales } \\
& \mathrm{n}=\text { Número de meses }
\end{aligned}
$$

Con los resultados promedio mensuales de cada estación, se procedió a crear un mapa de precipitaciones mediante el método de Polígonos de Thiessen (Villon 2004).

\section{Paso 3: Estimación de la Evapotranspiración Potencial (ETP)}

Al igual que en la determinación de la distribución de las precipitaciones, fue necesario un convenio con el ICE y el IMN para tener acceso al registro de temperaturas, entre el año 2003 y 2006, de cinco estaciones meteorológicas que se encuentran próximas al área de estudio. Las estaciones de interés fueron: Santa Clara, La Marina, COOPELESCA, El Chato, Bajos del Toro y San Vicente. La temperatura promedio mensual se calculó de manera similar que la precipitación promedio mensual mediante la ecuación (1) (Gómez 2003): Una vez conocida la ubicación geográfica de estas estaciones, se creó un mapa de temperatura creado mediante el método de Polígonos de Thiessen.

Después de conocer los resultados promedio mensuales y anuales de temperatura, se procedió a determinar la Evapotranspiración Potencial (ETP) a través del método de Blaney \& Criddle (Schosinsky 2006). Este método es muy utilizado en Costa Rica y para su cálculo se requiere únicamente la temperatura media mensual y el porcentaje de horas luz solar mensual (Aparicio 1989). La ecuación (2) muestra el método de Blaney \& Criddle (Schosinsky 2006):

$$
\begin{aligned}
& \text { ETP }(\mathrm{mm} / \mathrm{mes})=(8,10+0,46 T) \text { Ps } \\
& \text { Donde: } \\
& \quad \mathrm{ETP}=\text { Evapotranspiración potencial en } \mathrm{mm} / \mathrm{mes} \\
& \mathrm{T}=\text { Temperatura media mensual en grados centígrados } \\
& \mathrm{Ps}=\text { Porcentaje de horas de luz solar mensual, con res- } \\
& \text { pecto al año }
\end{aligned}
$$

Para determinar el Ps, se utilizó el Cuadro 1, el cual muestra porcentajes de horas luz solar para la latitud $10^{\circ}$ del Hemisferio Norte, por ser la latitud en la que se localiza Costa Rica.

\section{Paso 4: Determinación del tipo de suelo}

Mediante el uso de un SIG, se elaboró un mapa digital que identifica los tipos de suelo persistentes en el área de estudio (ITCR 2004).

Se realizó un análisis físico de suelo en los distintos tipos de cobertura vegetal presentes en cada tipo de suelo. Para determinar la retención de humedad, se colectaron muestras de suelo con anillos de acero inoxidable, con dimensiones de $0,5 \times 2 \mathrm{~cm}$ de diámetro. Con ayuda de un martillo y un muestreador, los anillos se introdujeron en el suelo a una profundidad aproximada de $2 \mathrm{~cm}$, con ayuda de una pala pequeña, se extrajeron los anillos rellenos totalmente de suelo. En seguida, con una cuchilla, se limpió 
CUADRO 1

Porcentaje de horas de sol mensual en la Latitud $10^{\circ}$ del Hemisferio Norte

\begin{tabular}{lc}
\hline \multicolumn{1}{c}{ Mes } & Porcentaje de horas sol \\
\hline Enero & 8,13 \\
Febrero & 7,47 \\
Marzo & 8,45 \\
Abril & 8,37 \\
Mayo & 8,81 \\
Junio & 8,60 \\
Julio & 8,86 \\
Agosto & 8,71 \\
Setiembre & 8,25 \\
Octubre & 8,34 \\
Noviembre & 7,91 \\
Diciembre & 8,10 \\
Fuente: Custodio \& Llamas (1983) y elaboración propia.
\end{tabular}

cuidadosamente cada muestra y se le quito el suelo sobrante a los bordes de cada anillo, se envolvió cada muestra con papel aluminio y se empaco en una bolsa sellada, posteriormente, cada muestra se llevo al Laboratorio de Recursos Naturales de la Universidad de Costa Rica, donde fueron saturadas de humedad durante 24 horas, para posteriormente ser sometidas a presiones de 0,33bares (datos referentes a la capacidad de campo) y 15bares (datos referentes al punto de marchitez permanente), respectivamente.

Para determinar la densidad aparente ( $\rho$ a) del suelo, se colectaron muestras de suelo con cilindros de $10 \times 2 \mathrm{~cm}$ de diámetro, a $15 \mathrm{~cm}$ de profundad de suelo. La colecta se realizó de la misma manera como se obtuvieron las muestras de los anillos. En el Laboratorio de Recursos Naturales de la Universidad de Costa Rica, cada muestra fue pesada antes de someterla a una estufa a $110^{\circ} \mathrm{C}$ durante 24 horas, luego de haberse sometido a esta temperatura, las muestras fueron enfriadas y nuevamente pesadas. La diferencia entre la masa del suelo seco y el volumen del cilindro determinó la densidad aparente del suelo en cada una de las muestras. (Hernández \& Cabalceta 1999).

Para convertir la capacidad de campo (CC) y el punto de marchitez permanente (PMP), de porcentaje de humedad por peso de suelo seco (datos obtenidos en laboratorio) a porcentaje de humedad por volumen, se aplicó la ecuación (3):

$\%$ de humedad porvolumen $=(\%$ de humedad por peso de suelo seco) (densidad aparente)

\section{Paso 5: Estimación del tipo de cobertura vegetal del suelo}

Mediante el uso de un SIG y la foto aérea Encarta-2005 No 485p0351 (CENAT 2005) se creó un mapa digital que muestra el tipo de cobertura vegetal del suelo persistente en el área de estudio. Para cada tipo de cobertura vegetal del suelo, Schosinsky (2006) sugiere distintos coeficientes numéricos a considerar.

\section{Paso 6: Determinar los rangos de pendientes}

Se elaboró un mapa de elevación digital en el área de estudio mediante el uso de un SIG El mapa permitió agrupar áreas con igual pendiente o isopendientes. Para la pendiente predominante sobre la superficie, Schosinsky (2006) sugiere distintos coeficientes de pendiente.

\section{Paso 7: Estimación de la infiltración básica}

Mediante el uso de un SIG, se creó un mapa digital a partir de la superposición de 3 mapas que contenían el tipo de suelo, la pendiente y el tipo de cobertura del suelo. Este mapa se construyó considerando los límites o parteaguas de las microcuencas Palo, Marín y San Rafaelito. Los polígonos del mapa generado comparten las variables de cada uno de los tres mapas base. Las pruebas de infiltración se realizaron en cada polígono durante la época de invierno (mes de diciembre), cuando el suelo se encontraba más cerca de su saturación.

Se seleccionó el sitio para realizar la prueba evitando que estos fueran áreas compactadas con el peso de maquinaria, grietas, hormigueros o cualquier otra perturbación anormal del suelo (Orozco et al. 2003). El método utilizado es el conocido como infiltrómetro de doble anillo (Hernández \& Cabalceta 1999).

\section{Paso 8: Determinación de la profundidad de las raíces}

La profundidad de las raíces extractoras de agua según el tipo de cobertura vegetal del suelo, se determinaron según los valores propuestos por Schosinsky (2006). El tipo de cobertura del suelo utiliza parte de la humedad del suelo en el espacio ocupado por la raíces. Para convertir el porcentaje de humedad por volumen en $\mathrm{mm}$ de agua existentes en dicho espacio, se resolvió la ecuación (4):

$\mathrm{mm}$ de agua $=$ (porcentaje de humedad por volumen $)$ (profundidad de las raíces en $\mathrm{mm}$ ) 


\section{Paso 9: Determinación de la intercepción de la lluvia en el follaje}

Los valores referidos a la intercepción de la lluvia en el foIlaje según el tipo de cobertura vegetal del suelo, fueron determinados según lo propuesto por Schosinsky (2006). Si se hubiesen encontrado valores de precipitación iguales o menores a $5 \mathrm{~mm} / \mathrm{mes}$, entonces la retención de lluvia en el follaje hubiera sido igual a la precipitación (Schosinsky 2006).

\section{Paso 10: Determinación de la humedad inicial del suelo}

Para determinar la recarga potencial de agua hacia el acuífero, fue necesario conocer la humedad inicial del suelo en un mes determinado. En este caso, se consideró que en Costa Rica generalmente al final de la época de mayor precipitación, el suelo se encuentra a capacidad de campo. Uno de los criterios utilizados para seleccionar este mes fue determinar los meses consecutivos de agosto, septiembre y octubre, donde el suelo se encuentra a capacidad de campo, o cuando la precipitación que se infiltra mensualmente supera la evapotraspiración potencial mensual. En el último mes de la época lluviosa (octubre), la humedad del suelo final, fue igual a la capacidad de campo $(\mathrm{mm})$ y por tanto la humedad del suelo inicial en el mes siguiente (noviembre) también es igual a la capacidad de campo. Al final del ciclo anual, la humedad final calculada para el último mes, coincidió con la humedad inicial del mes de partida, la del mes con humedad conocida.

\section{Paso 11: Identificación de las ARH}

Mediante el uso de un SIG, se creó un mapa digital con las Áreas de Recarga Hídrica (ARH) que compartieron las mismas variables de precipitación, tipo de suelo, pendiente y cobertura vegetal del suelo, en cada microcuenca. En cada una de las $A R H$, se realizó un balance hídrico de suelos con el fin de estimar la cantidad de agua que drena del suelo hacia un posible acuífero que se encuentre ubicado debajo de éste.

\section{Paso 12: Balance hídrico de suelos para cada ARH}

Toda la información que se generó en los pasos anteriores sirvió de base para utilizar la hoja electrónica creada por Schosinsky (2006) para realizar el balance hídrico de suelos. Esta ecuación general permitió obtener diferentes valores, entre ellos y el que cumple enfáticamente con los objetivos de esta investigación, la cantidad potencial de agua que infiltra y recarga los acuíferos (Rp).

\section{Paso 13: Determinación del volumen de recarga en cada ARH}

El volumen de agua que recarga el acuífero, se determinó mediante la ecuación (5) (Schosinsky 2006):

$$
V=(R p)(A)
$$

Donde:

$\mathrm{V}=$ volumen de recarga en $\mathrm{m}^{3} / \mathrm{año}$

$\mathrm{Rp}=$ Recarga potencial al acuífero en $\mathrm{m} / \mathrm{año}$

$\mathrm{A}=$ Área donde se genera la recarga potencial en $\mathrm{m}^{2}$

\section{Paso 14: Categorización de las ARH}

Según los resultados de Recarga Potencial (Rp) obtenidos en el balance hídrico de suelos, las ARH se agruparon en tres categorías. La categorización que se definió se presenta en el Cuadro 2. A través del uso de un SIG, se creó un mapa digital que muestra la categoría a la que pertenece cada ARH, según sea su Rp.

\section{Paso 15: Definición de acciones de manejo para las ARH}

De manera participativa, en conjunto con líderes comunales en materia de ambiente y recurso hídrico, se definieron y validaron acciones de manejo con el fin de ser ejecutadas en las ARH identificadas. Para el desarrollo de esta propuesta se consideraron lineamientos legales, técnicos y administrativos.

\section{RESULTADOS}

El presente apartado se divide en tres sub-apartados con el fin de demostrar el cumplimiento de los objetivos específicos de la presente investigación. Los mismos se fundamentan en realizar una caracterización de variables biofísicas del área de estudio con el fin de crear un modelo biofísico conceptual que permita identificar Áreas de Recarga Hídrica (ARH) y definir acciones para su manejo.

\section{Caracterización de variables biofísicas para identificar ARH}

Distribución de la precipitación, temperatura y evapotranspiración potencial (ETP)

Para determinar la distribución de la precipitación, temperatura y evapotranspiración potencial (ETP), se consideró únicamente la información de las estaciones

CUADRO 2

Categorización de las $\mathrm{ARH}$, según los valores de Rp obtenidos

\begin{tabular}{ll}
\hline Rango de Rp ( $\mathbf{m}^{\mathbf{3}}$ /ha/año) & Categoría \\
\hline $18000-22000$ & Alta \\
$14000-17999.9$ & Madia \\
$10000-13999.9$ & Baja
\end{tabular}


meteorológicas de La Marina, COOPELESCA y San Vicente, esto debido a que son las estaciones que se encuentran más próximas al área de estudio. La información promedio mensual y anual de estas variables se presenta en los Cuadros 3,4 y 5 y corresponde al registro de tres años hidrológicos, considerando el periodo comprendido entre los meses de mayo del año 2003 y abril del año 2006.

El Cuadro 3 muestra que los meses comprendidos entre mayo y diciembre son los más lluviosos, presentando valores de precipitación mensual que oscilan entre 330 y $500 \mathrm{~mm}$, por tanto, es de esperar que estos meses sean también los de mayor infiltración y aporte a las aguas subterráneas. Igualmente, en los meses comprendidos entre enero y abril se presentan las precipitaciones menores con promedios que oscilan entre 90 y $300 \mathrm{~mm}$. Además, no se presentan grandes diferencias en los promedios anuales de precipitación de las tres estaciones meteorológicas, esto debido posiblemente a que en la zona predomina un clima moderadamente homogéneo y estable y a la poca extensión del área de estudio $\left(149 \mathrm{~km}^{2}\right)$. El promedio anual de precipitación para toda el área de estudio es de 4 185,3mm.

En el área de estudio se presenta una precipitación de tipo orográfica, originada cuando los vientos húmedos procedentes de las llanuras del norte y el Mar Caribe, ascienden al tener contacto con la cordillera volcánica central. El aire asciende, se enfría y se condensa, generando precipitaciones en las áreas de sotavento en distintos niveles del macizo montañoso. Como se ve en el Cuadro 3, el promedio de precipitación anual de $4113 \mathrm{~mm}$, es el más bajo y se presenta en la parte alta de las microcuencas (donde tiene influencia la estación meteorológica de San
Vicente), esto muy probablemente ocurre debido a que la condensación del agua se da en partes más bajas (Linsley et al. 1977).

En cuanto a la temperatura, el Cuadro 4 presenta valores muy estables durante todo el año, pero destaca el registro de datos más bajos en la parte alta de las microcuencas con un promedio anual de $17^{\circ} \mathrm{C}$, fenómeno causado por la influencia de vientos húmedos provenientes de la vertiente atlántica. En general, la temperatura promedio anual para toda el área de estudio es de $20,2^{\circ} \mathrm{C}$.

El Cuadro 5 muestra cierta estabilidad en los promedios mensuales de ETP con valores que oscilan entre $115 \mathrm{y}$ $165 \mathrm{~mm}$, esta estabilidad es congruente con los valores de temperatura que se presentan en el Cuadro 4. En la parte media de las microcuencas (con base en la información obtenida en las estaciones meteorológicas de La Marina y COOPELESCA), anualmente se presenta una mayor temperatura que induce una mayor ETP, la cual supera los valores dados en las partes altas, en más de $200 \mathrm{~mm}$.

Se nota también que en los meses de marzo y abril, la evapotranspiración es mayor que la precipitación, por lo que en estos meses no se da ningún aporte a las aguas subterráneas. Aun así, se debe mencionar que en los restantes 10 meses, la ETP es menor a la precipitación y es de esperarse una recarga hídrica importante. Específicamente entre los meses de junio y diciembre se presentan las mayores precipitaciones y consecuentemente es en estos meses donde hay mayores probabilidades de que el agua se infiltre, percole y recargue un posible acuífero en la zona.

CUADRO 3

Precipitación promedio mensual y anual para las estaciones meteorológicas de la Marina, COOPELESCA y San Vicente

\begin{tabular}{|c|c|c|c|c|c|c|c|c|c|c|c|c|c|c|}
\hline Estación & $\begin{array}{l}\text { Localización } \\
\text { Geográfica }\end{array}$ & \multicolumn{12}{|c|}{ Promedio de precipitación mensual (mm) } & $\begin{array}{c}\text { Promedio } \\
\text { anual } \\
(\mathrm{mm})\end{array}$ \\
\hline La Marina & $\begin{array}{l}\text { Lat. N } 10^{\circ} 22^{\prime} \\
\text { Long. O } 84^{\circ} 23^{\prime} \\
\text { Altitud: } 380 \mathrm{msnm}\end{array}$ & 247,6 & 176,9 & 120,3 & 136,6 & 361,1 & 456,8 & 474,0 & 450,0 & 425,2 & 463,3 & 434,1 & 421,1 & 4167 \\
\hline Coopelesca & $\begin{array}{l}\text { Lat. N } 10^{\circ} 19^{\prime} \\
\text { Long. O } 84^{\circ} 25^{\prime} \\
\text { Altitud: } 650 \mathrm{msnm}\end{array}$ & 301,0 & 163,0 & 112,0 & 110,0 & 340,5 & 426,4 & 501,8 & 466,0 & 495,4 & 500,5 & 414,2 & 445,2 & 4276 \\
\hline San Vicente & $\begin{array}{l}\text { Lat. N } 10^{\circ} 17^{\prime} \\
\text { Long. } 084^{\circ} 24^{\prime} \\
\text { Altitud: } 1450 \mathrm{msnm}\end{array}$ & 253,8 & 163,2 & 94,5 & 105,7 & 327,4 & 433,6 & 459,7 & 461,9 & 440,7 & 454,9 & 469,4 & 448,2 & 4113 \\
\hline
\end{tabular}


Con el método de Thiessen se creó un mapa con tres polígonos de igual Precipitación, Temperatura y ETP, delimitando así el rango de influencia de cada estación meteorológica dentro del área de estudio (Linsley et al. 1977). El mapa se muestra en la Fig. 1.

\section{Determinación del tipo de suelo}

En el área de estudio el orden de suelo Andisol se presenta sobre una geomorfología característica de colinas altas, conformada por rocas volcánicas heterogéneas que han sido afectadas por los procesos erosivos, tectónicos y el vulcanismo semi-explosivo de la cadena volcánica de la Cordillera Volcánica Central y el complejo volcánico Platanar (Laporte 1994).

Para Arenas et al. (1997), los materiales volcánicos corresponden a piroclastos, lavas, aglomerados, cenizas y tobas, modeladas por agentes geomorfico-tectónicos. Las rocas ígneas son principalmente del tipo brechas y lahares (Laporte 1994). El suelo es ligeramente pedregoso con reducido encharcamiento y nula inundación. La capa freática se encuentra aproximadamente a $1,4 \mathrm{~m}$ de profundidad y debido a la presencia de pendientes que oscilan entre los 10 y los $70^{\circ}$, la evidencia de erosión es moderada, ello considerando el tipo de cobertura vegetal predominante en la zona (MAG 2000).

Según Alvarado et al. (2001), debido a la presencia de altos contenidos de compuestos organominerales estables, especialmente en el horizonte superficial, los Andisoles resultan ser suelos muy bien estructurados que propician el buen drenaje, pero a su vez, presentan una buena retención de humedad. La profundidad de estos suelos puede alcanzar hasta 1,5m. En cuatro Andisoles

\section{CUADRO 4}

Temperatura promedio mensual y anual para las estaciones meteorológicas de la Marina, COOPELESCA y San Vicente

\begin{tabular}{|c|c|c|c|c|c|c|c|c|c|c|c|c|c|c|}
\hline \multirow{2}{*}{ Estación } & \multirow{2}{*}{$\begin{array}{l}\text { Localización } \\
\text { Geográfica }\end{array}$} & \multicolumn{12}{|c|}{ Promedio de temperatura mensual $\left({ }^{\circ} \mathrm{C}\right)$} & \multirow{2}{*}{$\begin{array}{l}\text { Promedio } \\
\text { anual }\left({ }^{\circ} \mathrm{C}\right)\end{array}$} \\
\hline & & Ene & Feb & Mar & Abr & May & Jun & Jul & Ago & Set & Oct & Nov & Dic & \\
\hline La Marina & $\begin{array}{l}\text { Lat. N } 10^{\circ} 22^{\prime} \\
\text { Long. } \mathrm{O} 84^{\circ} 23^{\prime} \\
\text { Altitud: } 380 \mathrm{msnm}\end{array}$ & 20,3 & 21,1 & 21,6 & 22,3 & 23,4 & 23,0 & 22,3 & 22,5 & 23,1 & 22,6 & 21,7 & 20,6 & 22,0 \\
\hline Coopelesca & $\begin{array}{l}\text { Lat. N } 10^{\circ} 19^{\prime} \\
\text { Long. } 084^{\circ} 25^{\prime} \\
\text { Altitud: } 650 \mathrm{msnm}\end{array}$ & 21,1 & 21,3 & 21,7 & 22,4 & 22,7 & 22,5 & 21,9 & 22,2 & 22,5 & 21,8 & 21,6 & 21,0 & 21,8 \\
\hline San Vicente & $\begin{array}{l}\text { Lat. N } 10^{\circ} 17^{\prime} \\
\text { Long. } 084^{\circ} 24^{\prime} \\
\text { Altitud: } 1450 \mathrm{msnm}\end{array}$ & 16,0 & 16,3 & 16,7 & 17,3 & 17,8 & 17,7 & 17,5 & 17,5 & 17,5 & 17,3 & 16,9 & 16,5 & 17,0 \\
\hline
\end{tabular}

Fuente: ICE \& IMN (2007) y elaboración propia

CUADRO 5

ETP promedio mensual y anual para las estaciones meteorológicas de la Marina, COOPELESCA y San Vicente

\begin{tabular}{|c|c|c|c|c|c|c|c|c|c|c|c|c|c|c|}
\hline \multirow{2}{*}{ Estación } & \multirow{2}{*}{$\begin{array}{l}\text { Localización } \\
\text { Geográfica }\end{array}$} & \multicolumn{12}{|c|}{ Promedio de ETP mensual } & \multirow{2}{*}{$\begin{array}{l}\text { Promedio } \\
\text { ETP anual }\end{array}$} \\
\hline & & Ene & Feb & Mar & Abr & May & Jun & Jul & Ago & Set & Oct & Nov & Dic & \\
\hline La Marina & $\begin{array}{l}\text { Lat. N } 10^{\circ} 22^{\prime} \\
\text { Long. O } 84^{\circ} 23^{\prime} \\
\text { Altitud: } 380 \mathrm{msnm}\end{array}$ & 140,3 & 131,6 & 150,8 & 152,0 & 164,3 & 158,9 & 160,9 & 159,0 & 152,8 & 152,6 & 141,5 & 140,9 & 1806 \\
\hline Coopelesca & $\begin{array}{l}\text { Lat. N } 10^{\circ} 19^{\prime} \\
\text { Long. O } 84^{\circ} 25^{\prime} \\
\text { Altitud: } 650 \mathrm{msnm}\end{array}$ & 143,2 & 132,3 & 151,2 & 152,4 & 161,6 & 156,9 & 159,3 & 157,8 & 150,6 & 149,6 & 141,1 & 142,4 & 1798 \\
\hline San Vicente & $\begin{array}{l}\text { Lat. N } 10^{\circ} 17^{\prime} \\
\text { Long. } 084^{\circ} 24^{\prime} \\
\text { Altitud: } 1450 \mathrm{msnm}\end{array}$ & 124,6 & 115,5 & 132,2 & 133,2 & 142,1 & 138,4 & 141,8 & 139,4 & 132,0 & 132,7 & 124,4 & 126,0 & 1582 \\
\hline
\end{tabular}

Fuente: ICE \& IMN (2007) y elaboración propia. 


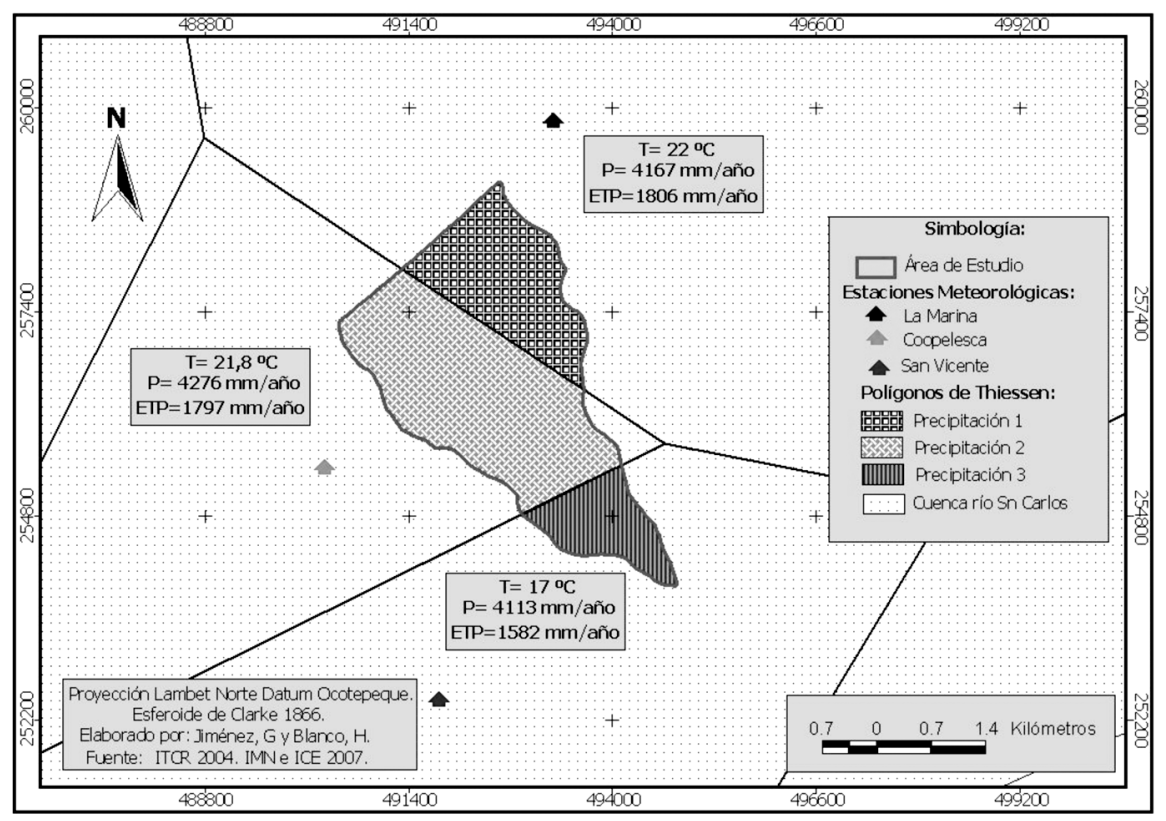

FIG. 1. Precipitación media del área de estudio según registros de las estaciones meteorológicas de La Marina, COOPELESCA y San Vicente.

estudiados, Alvarado et al. (2005) encontró una alta capacidad volumétrica para retener el agua disponible, con valores entre 10 y $30 \%$.

Los suelos Andisoles presentan una baja densidad aparente (pa) que favorece una alta velocidad de infiltración cuando no se presentan capas endurecidas en la superficie o a poca profundidad (Alvarado et al. 2001). Según Alvarado et al. (2005), en 111 perfiles de Andisoles en Costa Rica, la pa en los primeros $20 \mathrm{~cm}$ de profundidad del suelo, osciló entre 0,3 y $0,7 \mathrm{mg} / \mathrm{m}^{3}$.

Una característica notoria de los Andisoles es su elevado contenido de materia orgánica, lo cual influye sobre algunas de sus propiedades mencionadas, como su baja densidad aparente y alta capacidad para retener humedad. En general, los valores de materia orgánica decrecen con la profundidad del suelo y la mineralización de estos compuestos disminuye con la altura a nivel del mar, por lo que los contenidos de sustancias orgánicas son mayores en los pisos altitudinales mas fríos (Alvarado et al. 2001). En estudios realizados por Alvarado et al. (2001), en suelos Andisoles no se presentan valores de materia orgánica mayores a $18 \%$.

En partes cercanas a los volcanes, estos suelos son de textura franco arenosa o más gruesa, en las posiciones intermedias del relieve se presentan texturas franco-limosas o francas y en las partes inferiores ocurren texturas mayormente arcillosas, particularmente en el horizonte B. En general, en el horizonte A las texturas se caracterizan por presentar: $35-60 \%$ de arena, de $30-45 \%$ de limo y de 10 $25 \%$ de arcillas (Alvarado et al. 2001).

En el área de estudio se identificaron tres tipos de suelo Andisol, los cuales se muestran en la Fig. 2.

Según el ITCR (2004), los tipos de suelo 1 y 2, se clasifican dentro del grupo de los Dystrandept, con una profundidad del horizonte $A$ entre 0 y $40 \mathrm{~cm}$. El suelo tipo 1 se caracteriza por presentar pendientes entre 15 y $30 \%$ y en el suelo tipo 2 se presentan pendientes entre un $30 \mathrm{y}$ un $60 \%$. El tipo de suelo 3 pertenece al grupo de los $\mathrm{Hi}$ drandept, el cual se caracteriza por presentar pendientes mayores a $60 \%$, con una profundidad de $25 \mathrm{~cm}$ en el horizonte $\mathrm{A}$ y una mayor capacidad de retención de agua que los suelos 1 y 2 (Alvarado et al. 2001).

En los tres tipos de suelo se tomaron en total 10 muestras de suelo con el fin de determinar la capacidad que tiene el suelo para retener humedad, esta humedad está representada por la capacidad de campo (CC) y el punto de marchitez permanente (PMP). Para la misma cantidad de muestras se determinó la pa del suelo. En el Cuadro 6 se muestra el resultado del análisis físico de suelos.

En el Cuadro 6 se notan bajos valores promedio de pa: $0,7 \mathrm{mg} / \mathrm{m}^{3}$ en el tipo de suelo $1 ; 0,6 \mathrm{mg} / \mathrm{m}^{3}$ en el tipo de suelo 2 y $0,4 \mathrm{mg} / \mathrm{m}^{3}$ en el tipo de suelo 3 . Además, se 
muestra una mayor capacidad para almacenar humedad en el tipo de suelo 3, moderada capacidad de almacenamiento en el tipo de suelo 2 y menor capacidad de almacenamiento en el suelo 1.

Según Alvarado et al. (2001) los valores de pa que en este caso oscilan entre 0,30 y $0,80 \mathrm{mg} / \mathrm{m}^{3}$, son comunes en suelos de origen volcánico, los cuales se caracterizan por ser poco densos debido: (a) poseen minerales amorfos o alófanas con un tamaño de arcillas menor a 0,002 mm, (b) presentan altos contenidos de materia orgánica y (c) contienen un amplio espacio poroso. Las anteriores características justifican la ocurrencia de un suelo joven con un grado considerable de meteorización (Alvarado et al. 2005).

En general, comparando los valores de retención de humedad y pa obtenidos por Alvarado et al. (2005) con los resultados obtenidos en este caso, en el área de estudio se presenta una alta capacidad de retención de humedad, altos valores de CC y bajos valores de pa.

Como complemento al análisis de retención de humedad y $\rho a$, se realizaron análisis de textura de suelo en el laboratorio del Instituto Nacional de Investigación y Transferencia en Tecnología Agropecuaria (INTA). Los valores obtenidos en cinco muestras de suelo fueron: $47 \%$ de arena, $36 \%$ de limo y $17 \%$ de arcilla.

\section{Determinación del tipo de cobertura vegetal del suelo}

La Fig. 3 muestra la distribución del tipo de cobertura vegetal del suelo que se presenta dentro del área de estudio.
A cada tipo de cobertura vegetal del suelo, se le asignó un coeficiente. Dicha asignación se describe en el Cuadro 7.

La extensión de cada tipo de cobertura vegetal del suelo, se presenta en el Cuadro 8.

En el Cuadro 8 se nota que un 54\% del área de estudio es bosque, algo que sin duda favorece la infiltración del agua en el suelo y su protección. Del restante $46 \%$ del área de estudio, casi la mitad (un 22\%) se encuentra cubierto por pastizales dedicados a la producción agropecuaria, actividad que amenaza con compactar y contaminar los suelos, los cuales, funcionan como medio de infiltración de las aguas subterráneas. El restante 24\% del territorio está cubierto por caña y zonas agroforestales (zacate y árboles).

\section{Determinación de la pendiente en porcentaje}

El mapa digital de pendientes muestra que dentro del área de estudio existen áreas muy poco significativas con pendiente menor a $7 \%$, por tanto se consideró un coeficiente de pendiente (Kp) igual a 0,06.

\section{Determinación de la infiltración básica (fc)}

Se realizaron 19 pruebas de infiltración básica en las áreas que comparten las variables de tipo de suelo, pendiente y tipo de cobertura vegetal del suelo. El resultado de las pruebas de infiltración se presenta en el Cuadro 10.

El Cuadro 9 muestra como los valores de fc en general, son mayores en suelo cubierto de bosque y menores en

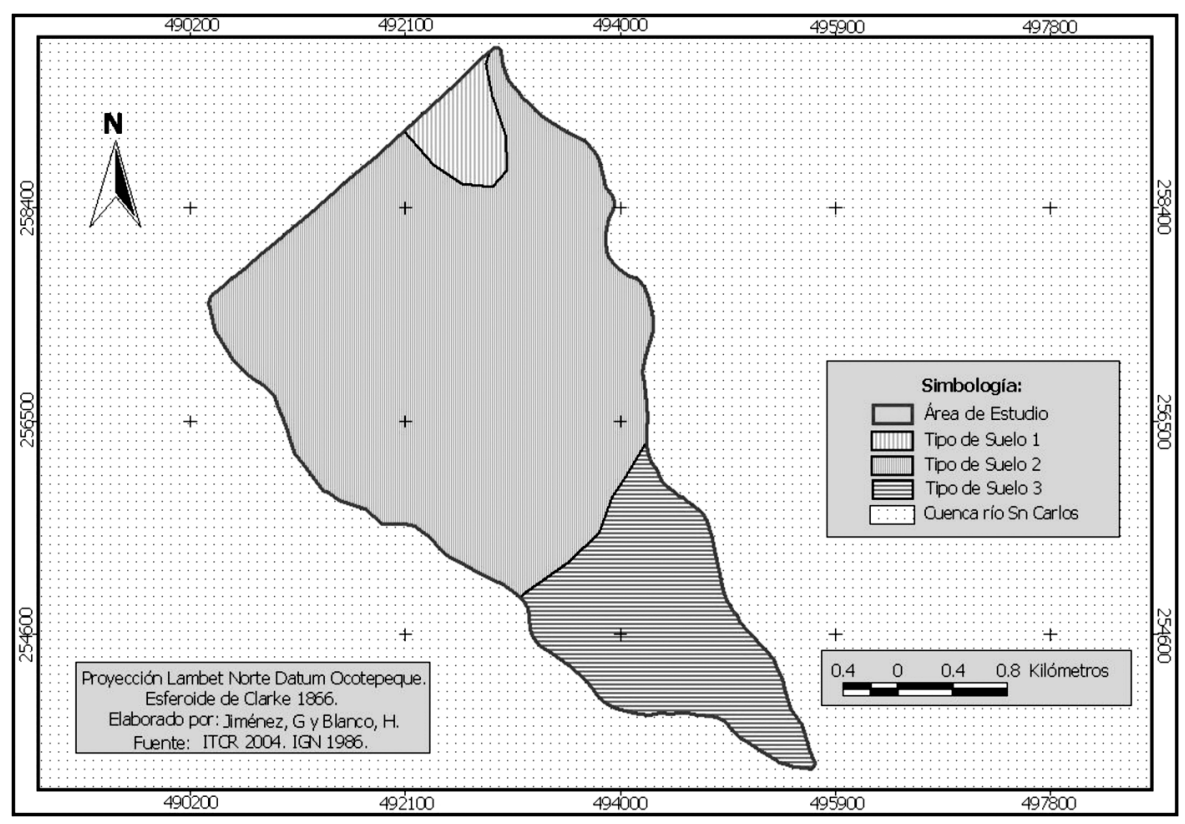

FIG. 2. Tipos de suelo identificados dentro del área de estudio. 


\section{CUADRO 6}

Resultado de los análisis físicos de suelo en relación a su densidad aparente y su capacidad de retener agua

\begin{tabular}{|c|c|c|c|c|c|}
\hline \multirow{2}{*}{$\begin{array}{l}\text { Número de } \\
\text { muestra }\end{array}$} & \multirow{2}{*}{$\begin{array}{l}\text { Tipo y cobertura } \\
\text { del suelo }\end{array}$} & \multirow{2}{*}{$\begin{array}{l}\text { Densidad } \\
\text { aparente } \\
(\mathrm{mg} / \mathrm{m} 3)\end{array}$} & \multicolumn{2}{|c|}{ Retención de humedad (\%) } & \multirow{2}{*}{$\begin{array}{l}\text { Agua } \\
\text { útil (\%) }\end{array}$} \\
\hline & & & $\begin{array}{l}\text { 0,33 Bares de } \\
\text { presión (CC) }\end{array}$ & $\begin{array}{c}15 \text { Bares de } \\
\text { presión (PMP) }\end{array}$ & \\
\hline 1 & Tipo de suelo 1 - Bosque & 0,6 & 82,4 & 72,3 & 10,0 \\
\hline 2 & Tipo de suelo 1 - Caña & 0,7 & 86,3 & 75,0 & 11,3 \\
\hline 3 & Tipo de suelo 2 - Bosque & 0,7 & 110,1 & 100,1 & 10,0 \\
\hline 4 & Tipo de suelo 2 - Zacate 50\% & 0,5 & 129,4 & 119,8 & 9,6 \\
\hline 5 & Tipo de suelo 2 - Pastizal & 0,8 & 98,2 & 89,2 & 9,0 \\
\hline 6 & Tipo de suelo 2 - Zacate 75\% & 0,3 & 250,2 & 225,8 & 24,3 \\
\hline 7 & Tipo de suelo 2 - Caña & 0,5 & 125,7 & 113,4 & 12,2 \\
\hline 8 & Tipo de suelo 3 - Zacate 50\% & 0,3 & 192,8 & 175,0 & 17,7 \\
\hline 9 & Tipo de suelo 3 - Bosque & 0,4 & 171,6 & 151,3 & 20,2 \\
\hline 10 & Tipo de suelo 3 - Zacate 75\% & 0,4 & 170,2 & 156,3 & 13,9 \\
\hline
\end{tabular}

Fuente: CIA 2007 y elaboración propia.

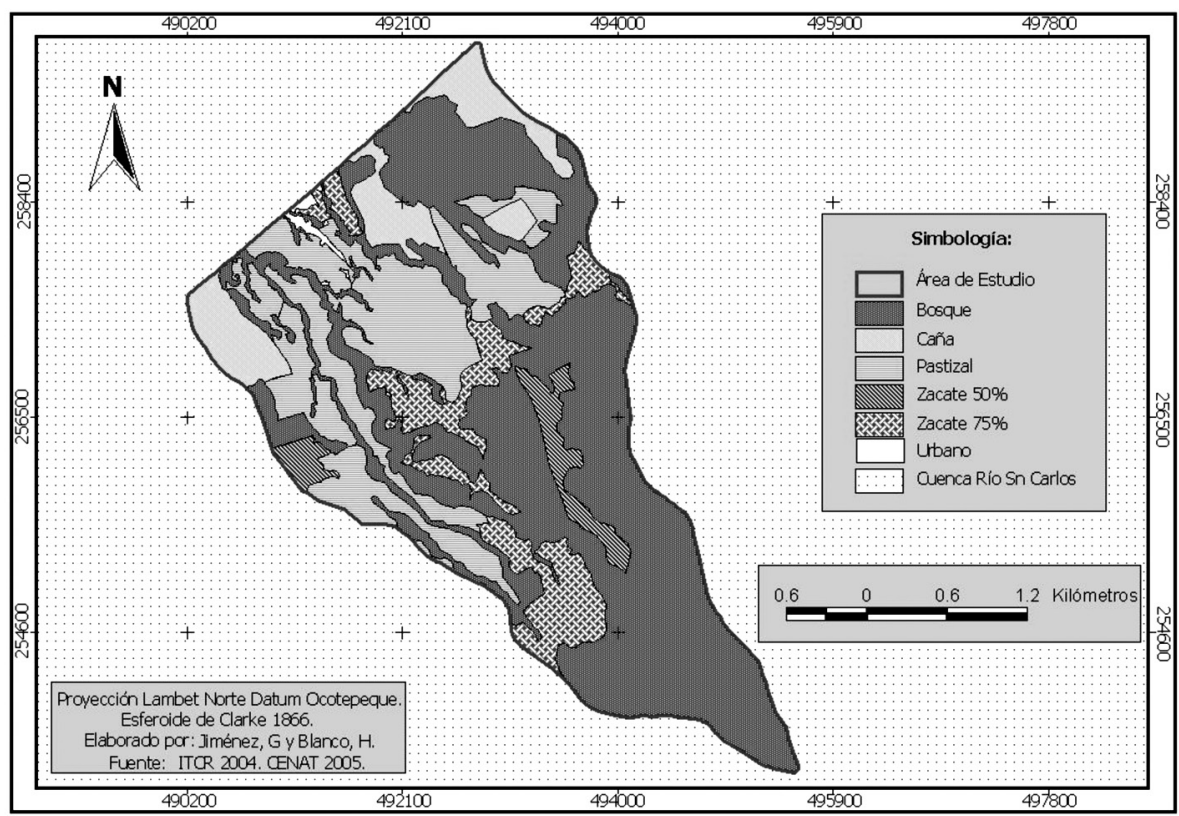

FIG. 3. Tipo de cobertura vegetal del suelo dada en el área de estudio.

suelos cubiertos por pastizal y caña. Las coberturas de suelo con zacate $50 \%$ y $75 \%$ presentan valores intermedios.

Según Alvarado et al. (2001), en dos Andisoles de la meseta central donde se realizaron pruebas de fc, los valores que se obtuvieron oscilaron entre 6 y $24 \mathrm{~cm} /$ hora. Al comparar los datos de Alvarado et al. (2001) con los datos obtenidos en esta investigación, se puede afirmar que solo 7 de las 19 pruebas están dentro de ese rango y 5 de la 7 pruebas se realizaron en suelo cubierto por bosque. Las restantes 12 pruebas presentan valores inferiores a 6 , 
fenómeno que puede ser causado, ya sea por la compactación que la ganadería ejerce sobre del suelo o por la predominancia de altas pendientes en toda el área de estudio (ITCR 2004).

\section{Determinación de la profundidad de las raíces extractoras de agua}

La profundidad de las raíces estimada para cada tipo de cobertura del suelo, se muestra en el Cuadro 10.

\section{Determinación de la intercepción de lluvia en el follaje}

El Cuadro 11 muestra el porcentaje de retención de agua en el follaje según el tipo de cobertura vegetal del suelo.

\section{CUADRO 7}

Coeficientes sugeridos para los diferentes tipos de cobertura vegetal presentes en el área de estudio

\begin{tabular}{lc}
\hline \multicolumn{1}{c}{ Cobertura vegetal } & $\begin{array}{c}\text { Coeficiente } \\
\text { (Kv) }\end{array}$ \\
\hline $\begin{array}{l}\text { Cobertura con zacate en una proporción } \\
\text { menor a 50\% }\end{array}$ & 0,09 \\
Terrenos cultivados (Caña) & 0,1 \\
Cobertura con pastizal & 0,18 \\
Bosques & 0,2 \\
Cobertura con zacate en una proporción & 0,21 \\
mayor a 75\% & \\
Fuente: Schosinsky (2006) y elaboración propia. &
\end{tabular}

CUADRO 8

Extensión de los tipos de cobertura vegetal del suelo

\begin{tabular}{lrrr}
\hline \multirow{2}{*}{ Cobertura vegetal del suelo } & \multicolumn{3}{c}{ Extensión } \\
\cline { 2 - 4 } & \multicolumn{1}{c}{ ha } & $\left.\mathbf{( k m}^{2}\right)$ & (\%) \\
\hline $\begin{array}{l}\text { Cobertura con zacate en una } \\
\text { proporción menor a 50\% }\end{array}$ & 51,5 & 0,5 & 3,4 \\
Terrenos cultivados (Caña) & 149,4 & 1,5 & 10,0 \\
Cobertura con pastizal & 323,9 & 3,2 & 21,7 \\
Bosques & 807,0 & 8,1 & 54,1 \\
Cobertura con zacate en una & 153,6 & 1,5 & 10,3 \\
proporción mayor a 75\% & & & \\
Urbano & 7,4 & 0,1 & 0,5 \\
Extensión del área de estudio & 1492,8 & 14,9 & 100,0
\end{tabular}

\section{Determinación de la humedad inicial del suelo en un mes} determinado

En el tradicional comportamiento climático de Costa Rica, Octubre es el último mes de la época lluviosa, por tanto, la humedad del suelo al final de este mes, es igual a la capacidad de campo (CC), entonces, la humedad del suelo al iniciar el mes de Noviembre, es también igual a la CC (Schosinsky 2006).

Noviembre es el mes con que se inicia el ciclo de humedad a través de todo el año, al cerrarse este ciclo, la humedad final en el mes de Octubre también debe ser igual a la CC.

\section{Modelo biofísico conceptual y balance hídrico de suelos para las ARH}

\section{Identificación de las ARH}

Se creó un mapa digital con las Áreas de Recarga Hídrica (ARH) que compartieron las variables de precipitación, tipo de suelo, pendiente y cobertura vegetal del suelo. En la Fig. 4, se muestra el mapa digital con las $25 \mathrm{ARH}$ identificadas.

\section{Determinación de la Rp}

En las 25 Áreas de Recarga Hídrica (ARH) identificadas, se aplicó la ecuación del balance hídrico de suelos propuesto por Schosinsky (2006).

El Cuadro 12 muestra un resumen de los resultados obtenidos en el balance hídrico de suelos aplicado a cada ARH. La información que es objeto de interés en la presente investigación se refiere a la Recarga Hídrica Potencial del Acuífero (Rp).

Como se muestra en el Cuadro 12, existe poca relación entre los valores de $\mathrm{Rp}$ y los tipos de cobertura vegetal del suelo, pues valores similares de Rp pueden ocurrir en distintos tipos de cobertura. Este fenómeno dado en cada ARH, es posiblemente generado por: (1) el grado de compactación que se presenta en las primeras capas del suelo, (2) la profundidad de las raíces extractoras de agua, (3) la evapotranspiración real (ETR) y 4) la pendiente.

En el Cuadro 12 también se presentan valores de $\mathrm{Rp}$ que van desde los 1064 hasta los 2 073mm/año, es difícil afirmar que estos valores sean altos o bajos, pues estos datos no se pueden comparar con otros estudios existentes, ya que ésta es la primer investigación que se realiza en la zona y en otros sitios ésta metodología se ha aplicado a una mayor escala, por lo que es difícil comparar y analizar con cercana realidad, los resultados obtenidos.

De manera general, los valores del total de resultados obtenidos en el balance hídrico de suelos aplicado a las 
CUADRO 9

Velocidad de infiltración del agua según la pendiente, el tipo de suelo y la cobertura vegetal del suelo

\begin{tabular}{cllcccr}
\hline $\begin{array}{c}\text { Número } \\
\text { de } \\
\text { prueba }\end{array}$ & Microcuenca & $\begin{array}{c}\text { Tipo de } \\
\text { cobertura }\end{array}$ & $\begin{array}{c}\text { Tipo de } \\
\text { suelo }\end{array}$ & $\begin{array}{c}\text { Velocidad de } \\
\text { infiltración } \\
\text { (cm/min) }\end{array}$ & $\begin{array}{c}\text { Velocidad de } \\
\text { infiltración } \\
\text { (cm/hora) }\end{array}$ & $\begin{array}{c}\text { Velocidad } \\
\text { Infiltración } \\
\text { (mm/día/m2) }\end{array}$ \\
\hline 1 & Palo & Bosque & 3 & 0,27 & 16,4 & 3936,0 \\
2 & Palo & Zacate 75\% & 3 & 0,01 & 0,6 & 144,0 \\
3 & Palo & Zacate 50\% & 3 & 0,02 & 1,2 & 288,0 \\
4 & Palo & Bosque & 2 & 0,39 & 23,6 & 5657,1 \\
5 & Palo & Zacate 75\% & 2 & 0,03 & 2,0 & 475,2 \\
6 & Palo & Zacate 50\% & 2 & 0,20 & 12,0 & 2880,0 \\
7 & Palo & Pastizal & 2 & 0,01 & 0,4 & 96,0 \\
8 & Palo & Caña & 2 & 0,03 & 2,0 & 475,2 \\
9 & Marín & Bosque & 2 & 0,10 & 6,0 & 1440,0 \\
10 & Marín & Zacate 75\% & 2 & 0,11 & 6,7 & 1598,4 \\
11 & Marín & Zacate 50\% & 2 & 0,01 & 0,6 & 144,0 \\
12 & Marín & Pastizal & 2 & 0,01 & 0,6 & 144,0 \\
13 & Marín & Caña & 2 & 0,05 & 2,8 & 672,0 \\
14 & Sn Rafaelito & Bosque & 2 & 0,11 & 6,3 & 1512,0 \\
15 & Sn Rafaelito & Zacate 75\% & 2 & 0,02 & 1,2 & 288,0 \\
16 & Sn Rafaelito & Pastizal & 2 & 0,03 & 1,6 & 384,0 \\
17 & Sn Rafaelito & Caña & 2 & 0,01 & 0,6 & 144,0 \\
18 & Sn Rafaelito & Bosque & 1 & 0,20 & 12,2 & 2937,6 \\
19 & Sn Rafaelito & Caña & 1 & 0,02 & 1,2 & 288,0 \\
& & & & &
\end{tabular}

CUADRO 10

Profundidad de las raíces extractoras de agua según el tipo de cobertura vegetal del suelo

\begin{tabular}{lcc}
\hline $\begin{array}{c}\text { Tipo de cobertura } \\
\text { vegetal del suelo }\end{array}$ & $\begin{array}{c}\text { Profundidad de } \\
\text { las raíces }(\mathbf{m})\end{array}$ & $\begin{array}{c}\text { Profundidad de } \\
\text { las raíces }(\mathbf{m m})\end{array}$ \\
\hline Bosques & 3 & 3000 \\
Zacate 75\% & 1,25 & 1250 \\
Zacate 50\% & 1,5 & 1500 \\
Pastizal & 1 & 1000 \\
Caña de Azúcar & 1,20 & 1200
\end{tabular}

CUADRO 11

Porcentaje de retención de lluvia en el follaje según el tipo de cobertura vegetal del suelo.

\begin{tabular}{lcc}
\hline $\begin{array}{l}\text { Tipo de Cobertura } \\
\text { Vegetal del Suelo }\end{array}$ & $\begin{array}{c}\text { Retención de } \\
\text { lluvia (\%) }\end{array}$ & $\begin{array}{c}\text { Coeficiente de } \\
\text { retención de lluvia } \\
\text { en el follaje }\end{array}$ \\
\hline Bosques & 20 & 0,20 \\
Zacate $75 \%$ & 12 & 0,12 \\
Zacate 50\% & 12 & 0,12 \\
Pastizal & 12 & 0,12 \\
Caña de Azúcar & 12 & 0,12 \\
Fuente: Schosinsky (2006) y elaboración propia.
\end{tabular}




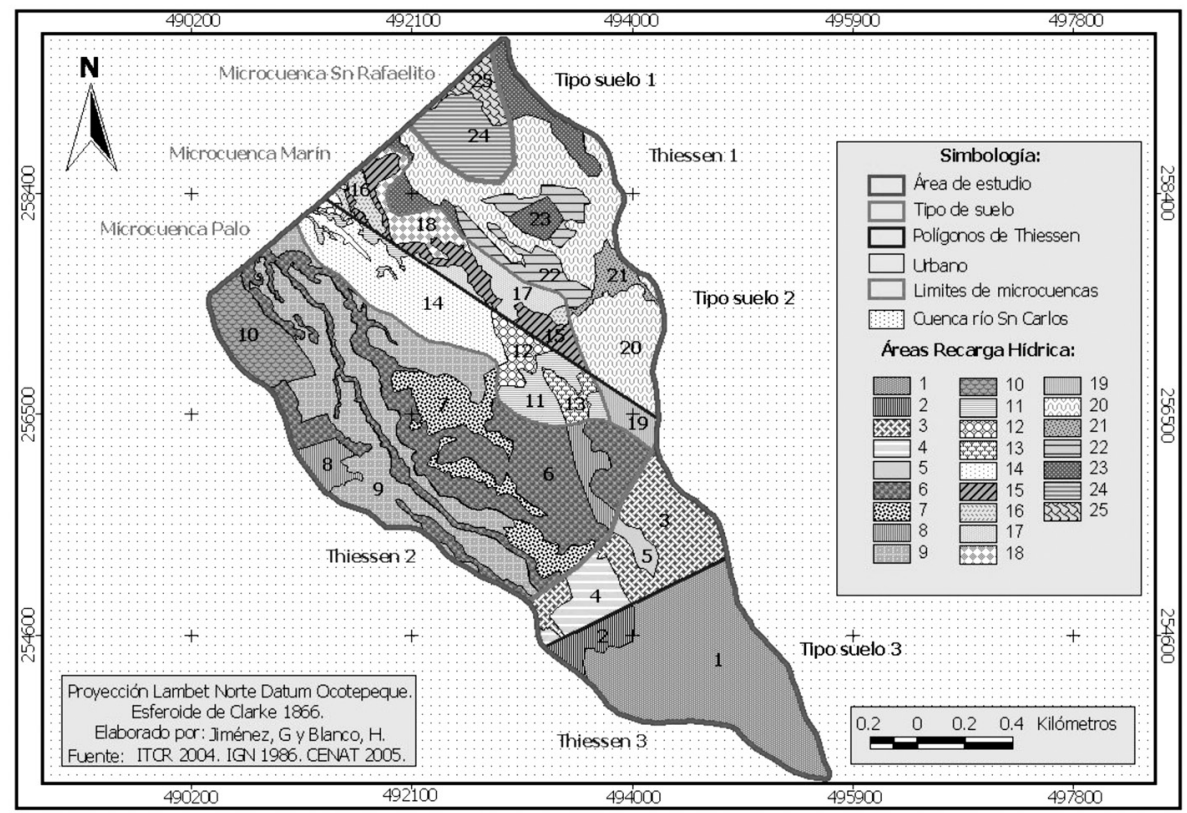

FIG. 4. ARH que compartieron las variables de precipitación, tipo de suelo, pendiente y cobertura vegetal del suelo.

25 ARH fueron, Precipitación $(P)=105488,3 \mathrm{~mm} / \mathrm{m}^{2}$; Precipitación que infiltra ( $\mathrm{Pi})=83960,7 \mathrm{~mm} / \mathrm{m}^{2}$; Retención de humedad en el follaje (Ret) $=15356,1 \mathrm{~mm} / \mathrm{m}^{2}$; Escorrentía superficial $(E s c)=6171,4 \mathrm{~mm} / \mathrm{m}^{2}$; Evapotrasnpiración real $(E T R)=4267,3 \mathrm{~mm} / \mathrm{m}^{2}$ y Recarga potencial del acuífero $(\mathrm{Rp})=41693,44 \mathrm{~mm} / \mathrm{m}^{2}$.

Según los datos anteriores, en total la precipitación que infiltra ( $\mathrm{Pi}$ ) es casi 14 veces mayor que la escorrentía superficial (Esc) y del agua que se precipita, un $40 \%$ llega a ser recarga potencial del acuífero (Rp). Esta conclusión permite suponer que debido a las distintas características que presentan variables biofísicas como la precipitación, la pendiente, el tipo de suelo y el tipo de cobertura vegetal, se cuenta con valores de recarga hídrica importantes en el área de estudio.

Si bien es cierto que en el área tienen influencia las altas precipitaciones, también es cierto que estas hacen posible una mayor evapotrasnpiración real (ETR), algo que se refleja en los resultados, donde un 50\% de la Pi no llega a ser parte de la recarga el acuífero y se evapotranspira.

\section{Determinación del volumen de Rp para cada ARH}

El volumen de Rp según la extensión total que comprenden las $25 \mathrm{ARH}$, se muestra en el Cuadro 13.

El Cuadro 13 muestra que en el territorio que comprende el área de estudio $\left(14,9 \mathrm{~km}^{2}\right)$, casi 24 millones de $\mathrm{m}^{3}$ de agua llegan a ser parte del agua subterránea cada año. Aunque no es posible comparar estos datos con otros resultados obtenidos, ya sea con esta u otras metodologías, si es claro que en la parte media-alta de las microcuencas Palo, Marín y San Rafaelito, se presentan variables biofísicas con características que favorecen la recarga de un posible acuífero existente en la zona.

En el Cuadro 14, aparece un resumen del total del volumen de recarga dado en la parte media-alta de las microcuencas Palo, Marín y San Rafaelito.

Según el Cuadro 14, en la microcuenca Palo es donde se da casi un $62 \%$ del total del volumen de agua que recarga en toda el área de estudio anualmente, no obstante, en las tres microcuencas recargan en promedio $1,6 \mathrm{~m}^{3}$ de agua por cada $\mathrm{m}^{2}$ durante todo el año.

\section{Categorización de las ARH}

En el Cuadro 15 se muestra la categorización de las Áreas de Recarga Hídrica (ARH), según los resultados de Recarga Hídrica Potencial del Acuífero (Rp) obtenidos en el balance hídrico de suelos.

En el Cuadro 15 se nota como ARH con distinta categoría se encuentran distribuidas en las tres microcuencas, además, predominan las ARH con recarga media y son menos las que presentan una baja recarga hídrica. También se nota que en las ARH cubiertas por bosque, aunque se 
CUADRO 12

Recarga hídrica potencial del acuífero (Rp) en las 25 ARH

\begin{tabular}{|c|c|c|c|c|c|}
\hline ARH & Microcuenca & Tipo Cobertura & Tipo Suelo & Precipitación & $\mathrm{Rp}(\mathrm{mm} / \mathrm{m} 2 / \mathrm{año}$ \\
\hline 1 & Palo & Bosque & 3 & 3 & 1744,5 \\
\hline 2 & Palo & Zacate $75 \%$ & 3 & 3 & 1610,4 \\
\hline 3 & Palo & Bosque & 3 & 2 & 1671,6 \\
\hline 4 & Palo & Zacate $75 \%$ & 3 & 2 & 1558,9 \\
\hline 5 & Palo & Zacate $50 \%$ & 3 & 2 & 1684,2 \\
\hline 6 & Palo & Bosque & 2 & 2 & 1677,0 \\
\hline 7 & Palo & Zacate $75 \%$ & 2 & 2 & 2061,6 \\
\hline 8 & Palo & Zacate $50 \%$ & 2 & 2 & 2065,8 \\
\hline 9 & Palo & Pastizal & 2 & 2 & 1092,4 \\
\hline 10 & Palo & Caña & 2 & 2 & 2072,1 \\
\hline 11 & Marín & Bosque & 2 & 2 & 1677,0 \\
\hline 12 & Marín & Zacate $75 \%$ & 2 & 2 & 2061,6 \\
\hline 13 & Marín & Zacate $50 \%$ & 2 & 2 & 1127,8 \\
\hline 14 & Marín & Pastizal & 2 & 2 & 1457,7 \\
\hline 15 & Marín & Bosque & 2 & 1 & 1570,4 \\
\hline 16 & Marín & Zacate $75 \%$ & 2 & 1 & 1931,0 \\
\hline 17 & Marín & Pastizal & 2 & 1 & 1334,0 \\
\hline 18 & Marín & Caña & 2 & 1 & 1937,5 \\
\hline 19 & San Rafaelito & Bosque & 2 & 2 & 1677,0 \\
\hline 20 & San Rafaelito & Bosque & 2 & 1 & 1570,4 \\
\hline 21 & San Rafaelito & Zacate $75 \%$ & 2 & 1 & 1931,0 \\
\hline 22 & San Rafaelito & Pastizal & 2 & 1 & 1941,5 \\
\hline 23 & San Rafaelito & Caña & 2 & 1 & 1064,9 \\
\hline 24 & San Rafaelito & Bosque & 1 & 1 & 1575,5 \\
\hline 25 & San Rafaelito & Caña & 1 & 1 & 1597,9 \\
\hline
\end{tabular}

Total de Rp 41693,4

espera que sean de alta recarga hídrica, todas se presentan con una recarga media, este hecho puede ser causado principalmente por los altos valores de evapotranspiración real (ETR) que se dan en el sitio, dejando menor cantidad de agua disponible para recargar los acuíferos. En el Cuadro 16 se muestra un resumen de la Recarga Hídrica Potencial (Rp) y las extensiones ocupadas por cada categoría.

Según el Cuadro 16, casi un $63 \%$ del área de estudio se encuentra en $\mathrm{ARH}$ con recarga media, las cuales representan casi un $65 \%$ del total del volumen de recarga hídrica.
Entonces, al conocer que todas las ARH cubiertas por bosque presentan recarga media, es posible suponer que es este tipo de cobertura vegetal el que actualmente está haciendo el principal aporte a la recarga de los acuíferos. Es claro también que aunque las ARH con recarga alta representan casi un $22 \%$ del total del volumen de recarga hídrica, estas solo aparecen en un $17 \%$ de área de estudio. Las ARH que presentan recarga baja, constituyen un $20 \%$ del área de estudio y representan un $14 \%$ del total del volumen de recarga hídrica. 
CUADRO 13

Volumen de Rp en las ARH

\begin{tabular}{|c|c|c|c|c|c|}
\hline ARH & Microcuenca & Cobertura & $\operatorname{Rp}(m / a n ̃ o)$ & Área $\left(m^{2}\right)$ & $\begin{array}{l}\text { Volumen Rp } \\
\text { (m³/año) }\end{array}$ \\
\hline 1 & Palo & Bosque & 1,7 & 1937100 & 3379271,0 \\
\hline 2 & Palo & Zacate $75 \%$ & 1,6 & 197500 & 318054,0 \\
\hline 3 & Palo & Bosque & 1,7 & 807600 & 1349984,2 \\
\hline 4 & Palo & Zacate $75 \%$ & 1,6 & 300000 & 467670,0 \\
\hline 5 & Palo & Zacate $50 \%$ & 1,7 & 87000 & 146525,4 \\
\hline 6 & Palo & Bosque & 1,7 & 2252600 & 3777610,2 \\
\hline 7 & Palo & Zacate $75 \%$ & 2,1 & 648800 & 1337566,1 \\
\hline 8 & Palo & Zacate $50 \%$ & 2,1 & 312200 & 644942,8 \\
\hline 9 & Palo & Pastizal & 1,1 & 2144100 & 2342214,8 \\
\hline 10 & Palo & Caña & 2,1 & 459700 & 952544,4 \\
\hline 11 & Marín & Bosque & 1,7 & 356500 & 597850,5 \\
\hline 12 & Marín & Zacate $75 \%$ & 2,1 & 189100 & 389848,6 \\
\hline 13 & Marín & Zacate $50 \%$ & 1,1 & 118900 & 134095,4 \\
\hline 14 & Marín & Pastizal & 1,5 & 585500 & 853483,4 \\
\hline 15 & Marín & Bosque & 1,6 & 386100 & 606331,4 \\
\hline 16 & Marín & Zacate $75 \%$ & 1,9 & 121400 & 234423,4 \\
\hline 17 & Marín & Pastizal & 1,3 & 255200 & 340436,8 \\
\hline 18 & Marín & Caña & 1,9 & 233700 & 452793,8 \\
\hline 19 & San Rafaelito & Bosque & 1,7 & 150700 & 252723,9 \\
\hline 20 & San Rafaelito & Bosque & 1,6 & 1721200 & 2702972,5 \\
\hline 21 & San Rafaelito & Zacate $75 \%$ & 1,9 & 146400 & 282698,4 \\
\hline 22 & San Rafaelito & Pastizal & 1,9 & 430000 & 834845,0 \\
\hline 23 & San Rafaelito & Caña & 1,1 & 490000 & 521801,0 \\
\hline 24 & San Rafaelito & Bosque & 1,6 & 452800 & 713386,4 \\
\hline \multirow[t]{2}{*}{25} & San Rafaelito & Caña & 1,6 & 163000 & 260457,7 \\
\hline & & & Total & 14947100 & 23894530,9 \\
\hline
\end{tabular}

La categorización y ubicación de cada ARH identificada aparece en la Fig. 5.

\section{Acciones de manejo sugeridas para las ARH}

\section{Determinación de acciones para el manejo de las ARH}

Al identificar las ARH, así como su capacidad para permitir la recarga de aguas subterráneas, es indispensable que para éstas se definan acciones de manejo que protejan y conserven el recurso hídrico subterráneo a mediano y largo plazo. A manera de consenso con la ASADA de San Juan, la Asociación Pro Fomento Ambiental de San Juan (APROFOA), el Comité Pro Bandera Azul Ecológica de San Juan y la Asociación de Desarrollo Integral de San Juan, se realizó un resumen de lineamientos legales, técnicos y administrativos a implementar en dichas áreas. El resumen que aparece en el Cuadro 19 es una línea base de acción y por lo tanto, ésta puede ser replanteada. Tanto la selección de los acciones de manejo, como la manera de implementarlos, debe ser competencia de las ASADAS, 
CUADRO 14

Volumen de recarga hídrica dado en la parte media-alta de las microcuencas Palo, Marín y San Rafaelito

\begin{tabular}{|c|c|c|c|c|}
\hline Microcuenca & Área $\left(m^{2}\right)$ & $\begin{array}{c}\text { Volumen Rp } \\
\text { (m³/año) }\end{array}$ & $\begin{array}{l}\text { Volumen } \\
\text { de Rp (\%) }\end{array}$ & $\begin{array}{l}\text { Volumen Rp } \\
\left(\mathrm{m}^{3} / \mathrm{m}^{2} / \mathrm{anno}\right)\end{array}$ \\
\hline Palo & 9146600 & 14716382,8 & 61,6 & 1,6 \\
\hline Marín & 2246400 & 3609263,2 & 15,1 & 1,6 \\
\hline San Rafaelito & 3554100 & 5568884,9 & 23,3 & 1,6 \\
\hline Total & 14947100 & 23894530,9 & 100,0 & \\
\hline
\end{tabular}

CUADRO 15

Categorización de las ARH según los resultados de Rp

\begin{tabular}{|c|c|c|c|c|c|c|}
\hline ARH & Microcuenca & $\begin{array}{c}\text { Tipo de } \\
\text { Cobertura }\end{array}$ & $\begin{array}{l}\text { Área } \\
\text { (ha) }\end{array}$ & $\begin{array}{c}\text { Volumen Rp } \\
\text { ( } m^{3 / a n ̃ o)}\end{array}$ & $\begin{array}{c}\text { Volumen Rp }\left(m^{3} /\right. \\
\text { ha/año) }\end{array}$ & Categoría \\
\hline 7 & Palo & Zacate 75\% & 64,9 & 1337566,1 & 20616 & Alta \\
\hline 8 & Palo & Zacate $50 \%$ & 31,2 & 644942,8 & 20658 & Alta \\
\hline 10 & Palo & Caña & 46,0 & 952544,4 & 20721 & Alta \\
\hline 12 & Marín & Zacate $75 \%$ & 18,9 & 389848,6 & 20616 & Alta \\
\hline 16 & Marín & Zacate $75 \%$ & 12,1 & 234423,4 & 19310 & Alta \\
\hline 18 & Marín & Caña & 23,4 & 452793,8 & 19375 & Alta \\
\hline 21 & San Rafaelito & Zacate $75 \%$ & 14,6 & 282698,4 & 19310 & Alta \\
\hline 22 & San Rafaelito & Pastizal & 43,0 & 834845,0 & 19415 & Alta \\
\hline 1 & Palo & Bosque & 193,7 & 3379271,0 & 17445 & Media \\
\hline 2 & Palo & Zacate $75 \%$ & 19,8 & 318054,0 & 16104 & Media \\
\hline 3 & Palo & Bosque & 80,8 & 1349984,2 & 16716 & Media \\
\hline 4 & Palo & Zacate $75 \%$ & 30,0 & 467670,0 & 15589 & Media \\
\hline 5 & Palo & Zacate $50 \%$ & 8,7 & 146525,4 & 16842 & Media \\
\hline 6 & Palo & Bosque & 225,3 & 3777610,2 & 16770 & Media \\
\hline 11 & Marín & Bosque & 35,7 & 597850,5 & 16770 & Media \\
\hline 14 & Marín & Pastizal & 58,6 & 853483,4 & 14577 & Media \\
\hline 15 & Marín & Bosque & 38,6 & 606331,4 & 15704 & Media \\
\hline 19 & San Rafaelito & Bosque & 15,1 & 252723,9 & 16770 & Media \\
\hline 20 & San Rafaelito & Bosque & 172,1 & 2702972,5 & 15704 & Media \\
\hline 24 & San Rafaelito & Bosque & 45,3 & 713386,4 & 15755 & Media \\
\hline 25 & San Rafaelito & Caña & 16,3 & 260457,7 & 15979 & Media \\
\hline 9 & Palo & Pastizal & 214,4 & 2342214,8 & 10924 & Ваја \\
\hline 13 & Marín & Zacate $50 \%$ & 11,9 & 134095,4 & 11278 & Baja \\
\hline 17 & Marín & Pastizal & 25,5 & 340436,8 & 13340 & Baja \\
\hline \multirow[t]{2}{*}{23} & San Rafaelito & Caña & 49,0 & 52801,0 & 10649 & Baja \\
\hline & & Total & 1494,7 & 23894530,9 & 416937 & \\
\hline
\end{tabular}


CUADRO 16

Rp y extensión de las categorías a las que pertenece cada ARH

\begin{tabular}{|c|c|c|c|c|}
\hline \multirow{2}{*}{ Categoría } & \multicolumn{2}{|c|}{ Recarga Hídrica Potencial (Rp) } & \multicolumn{2}{|c|}{ Extensión } \\
\hline & $\mathrm{m}^{3} / \mathrm{año}$ & $\%$ & Hectáreas & $\%$ \\
\hline Alta & 5129662,3 & 21,5 & 254,1 & 17,0 \\
\hline Media & 15426320,5 & 64,6 & 939,8 & 62,9 \\
\hline Baja & 3338548,1 & 14,0 & 300,8 & 20,1 \\
\hline Total & 23894530,9 & 100,0 & 1494,7 & 100,0 \\
\hline
\end{tabular}

hidroeléctrica El Embalse S.A, grupos organizados, productores locales, municipalidad, sector institucional y técnicos en la materia.

\section{DISCUSIÓN}

El área de estudio recibe en promedio $4185 \mathrm{~mm}$ anuales de precipitación, algo que puede ser importante en términos de recarga, pues si no hay precipitaciones, la recarga es nula, a no ser que esta se dé debido a la infiltración de las aguas superficiales presentes en los ríos, lagos y lagunas, o a partir del agua proveniente de otro sistema acuífero. No obstante, los resultados demuestran que la temperatura promedio anual de $20,2^{\circ} \mathrm{C}$ y el tipo de cobertura vegetal, inducen la evapotranspiración potencial (ETP), provocando que no toda el agua que se precipita se retenga en el suelo o percole para ser parte de la recarga de agua subterránea.

Únicamente en los meses de marzo y abril, la ETP es mayor a la precipitación y por tanto, la recarga potencial del acuífero (Rp) se ve reducida y es posible que ésta se dé solo a partir del agua retenida en el suelo durante los meses anteriores. Este suceso es congruente con lo mencionado por Ochoa (2007), quien menciona que es en estos meses cuando el caudal de los manantiales que abastecen de agua potable a la comunidad de San Juan, merman considerablemente. En general, es de suma importancia la planificación y manejo que se le dé a las 25 Áreas de Recarga Hídrica (ARH) identificadas, con el fin de mantener y aumentar el caudal de los 10 manantiales que abastecen de agua potable a una población aproximada de 6500 habitantes de las comunidades de San Juan, San Luís, Linda Vista, el Quiosco y Monte Oreb.

FIG. 5. Categorización de ARH.

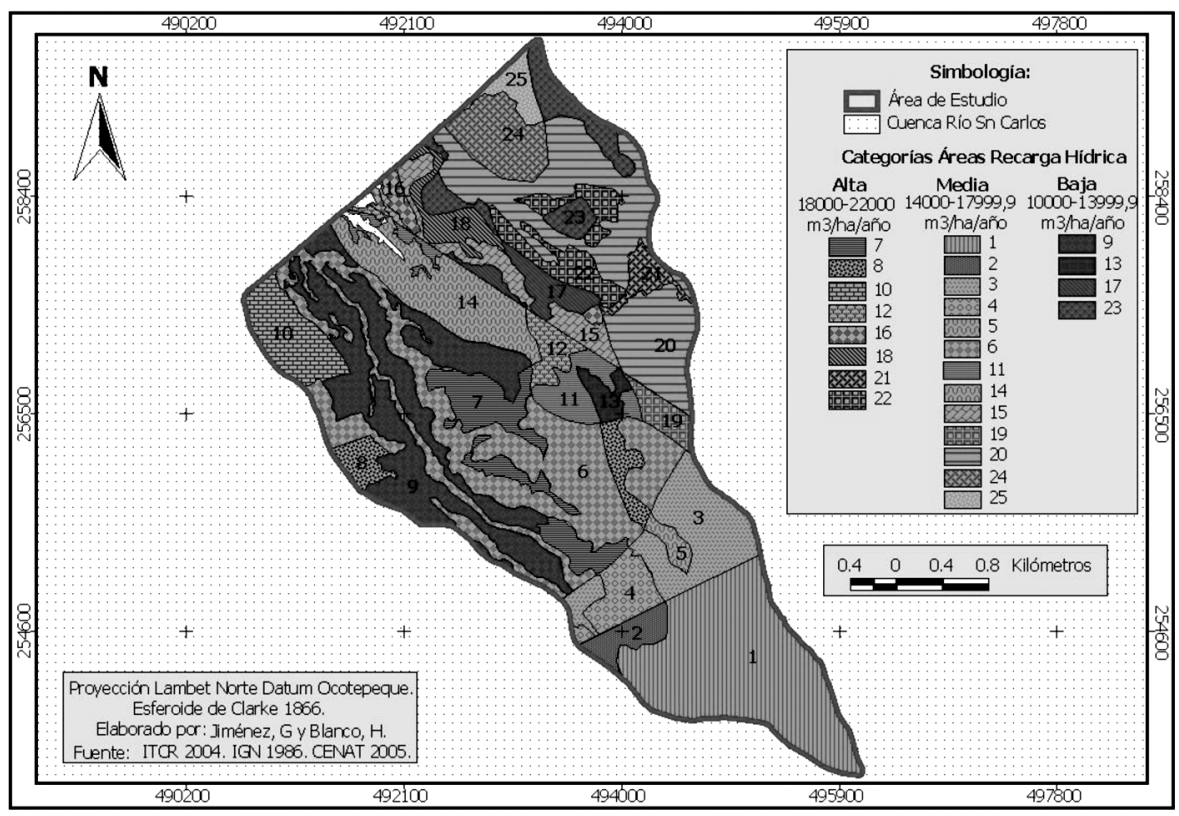




\section{CUADRO 17}

Acciones de manejo sugeridas para las ARH

(I) Crear conciencia en productores y población local para velar porque se respete la legislación ambiental vigente. Las leyes de agua, agua potable, forestal, conservación de la vida silvestre, uso y conservación de suelos, ordenamiento territorial y otras relacionadas con la protección y conservación del recurso hídrico, deben considerarse antes de desarrollar cualquier tipo de actividad en la zona. La promoción del dialogo y consenso con los infractores de estas leyes debe privar, antes de iniciar con los respectivos tramites de denuncias por delitos ambientales.

(II) El Ministerio de Ambiente, Energía y Telecomunicaciones (MINAET) en conjunto con ASADAS y población local deben velar por proteger la cobertura en su mayoría boscosa, en las 540ha (un 36\% del área de estudio) bajo propiedad privada que se encuentran dentro del Parque Nacional del Agua Juan Castro Blanco (PNAJCB). Prioritariamente estas 540ha deben ser objeto de indemnización o convenio de manejo entre propietarios y entes interesados en proteger y conservar el recurso hídrico.

(III) En su mayoría, los manantiales se encuentran en zonas sin bosque o con poca cobertura boscosa, ello aunado a la alta capacidad de infiltración del suelo, hace ver la necesidad de determinar las áreas de protección de estos manantiales con el

Legal fin de contrarrestar las amenazas por su contaminación. Por lo tanto, se debe respetar la protección de 200m alrededor de (L) manantiales utilizados para consumo humano (según la Ley de Aguas № 276) y $100 \mathrm{~m}$ alrededor de los manantiales no utilizados para consumo humano (según la Ley Forestal № 7575).

(IV) Reforestación con especies nativas en 15m de los márgenes de los ríos Palo, Marín y San Rafaelito, según lo dispuesto por el reglamento de la Ley Forestal № 7575.

(V) Sobreponer el mapa de ARH con el mapa de tenencia de tierras, con el fin de definir estrategias de manejo o adquisición de las $\mathrm{ARH}$, ya sea compra, indemnización, donación, protección por parte del estado, entre otras.

(VI) Los planes reguladores y de ordenamiento territorial que a nivel de la Municipalidad de San Carlos, MINAET u otras organizaciones quieran implementarse en la zona, pueden considerar los resultados de la presente investigación, Para ello es importante que organizaciones, productores e interesados en el manejo y conservación del recurso hídrico, mantengan una relación cercana con estas instituciones $u$ organizaciones y ser parte integral de la toma de dediciones.

(VII) Declarar vía decreto ejecutivo "Zona de Protección" a aquellas ARH que así lo ameriten.

(I) Desarrollar e implementar un Plan de Manejo Integral (PMI) de las tres microcuencas, que prevenga el bienestar socioeconómico de la población y ordene el crecimiento productivo de la zona. Los resultados de recarga media y baja obtenidos en la mayor parte del área de estudio, incitan a la pronta recuperación, protección y conservación de las ARH, lo cual ha de ser el punto de partida de este PMI.

(II) Crear un Programa de Producción Sostenible para ser implementado en las tres microcuencas, este programa puede ser integrado por universidades, instituciones públicas competentes, organizaciones comunales y productores locales. Se deben contemplar actividades de educación ambiental, agroforestería, técnicas agrosilvopastoriles y turísticas que vengan a contribuir con el ingreso económico de los productores y con la protección del recurso hídrico subterráneo. La implementación de este programa da la oportunidad de obtener incentivos como financiamiento de actividades productivas, pago por servicios ambientales (PSA), finca ecológica, certificaciones de producción orgánica y Certificados de Sostenibilidad Turística (CST). El desarrollo de este programa debe contemplar y respetar aspectos sociales, culturales y económicos, propios de la población local.

(III) Con base en los resultados de recarga potencial del acuífero (Rp), se pueden establecer clases de uso del territorio que considere la presencia de corredores biológicos, protección de manantiales, protección de ríos, áreas productivas de alta, media y baja intensidad y áreas recreativas o de desarrollo turístico. Lo anterior es parte de una proposición de ordenamiento territorial en las tres microcuencas que concilie con la producción hídrica. Esa zonificación dará un mejor panorama en relación a la dirección, ritmo y capacidad de crecimiento en la zona, algo importante al conocer que en el área de estudio

Técnico

(T) existe relativamente poca urbanización y se esta a tiempo de planificar, promover y alcanzar un desarrollo congruente con la protección del recurso hídrico.

(IV) En las áreas de producción agropecuaria se deben promover prácticas de conservación de suelos y agua, reduciendo así, las tasas de erosión, escorrentía superficial, contaminación, evapotranspiración, sellamiento de poros y compactación, comunes en las técnicas de producción convencional. Algunas prácticas que pueden contribuir con la infiltración del agua superficial en los agroecosistemas presentes en el área de estudio, son las siguientes:

a. Debido a las pendientes que predominan, sembrar en curvas de nivel.

b. Subsolación y aradura profunda contra pendiente.

c. Construcción de zanjas o desagües de infiltración.

d. Siembra y manejo de árboles o plantaciones forestales con especies nativas.

e. Evitar la siembra de cultivos anuales, poco densos y de porte bajo, con el fin de evitar la transpiración,poco aporte de materia orgánica y baja protección de la compactación causada por la lluvia.

f. Siembra de cultivos perennes que no requieran acondicionamiento periódico del suelo.

g. Siembra de barreras y cercas vivas.

h. Siembra de especies arbóreas con buen desarrollo radicular para facilitar el movimiento de agua en el subsuelo.

i. Establecimiento de sistemas agroforestales con periodos rotacionales.

j. Asociación de cultivos con bajos requerimientos de humedad. 
k. Control biológico de plagas y evitar el uso de pesticidas.

I. Producción de biogás (biodigestores) a partir de excretas de bovinos.

m. Manejo de carga animal inferior a 1.3 animales/ha.

n. Uso de abonos orgánicos con el fin de aumentar el contenido de materia orgánica en los suelos.

o. Uso de biofertilizantes elaborados a partir de excretas animales y rastrojos de cultivo.

p. Uso de lombricompost elaborada a partir de excretas de bovinos.

q. Producción de carne con animales estabulados o semi estabulados.

r. Descanso de tierras (barbecho) en zonas que han sido de uso intensivo.

s. Evitar expansión de la frontera agropecuaria y promover la permanencia de árboles en un $30 \%$ de las propiedades.

t. Permitir la regeneración natural en chárrales, tacotales y bosque secundario.

(V) Promover la explotación turística sostenible mediante un plan de desarrollo turístico, donde el paisaje natural, la vida silvestre, actividades productivas y tradicionales y el trato amable de la población local, hacen posible atraer un segmento de turismo rural, ecológico, cultural y de observación de aves. Implementar actividades turísticas de baja carga e impacto en garantía del bienestar de las familias locales, contribuye con la protección y rehabilitación de aquellas ARH que a futuro, por su uso inadecuado, pueden reducir el volumen de recarga de las aguas subterráneas.

(VI) Se conoce que la capacidad de infiltración del suelo en el área de estudio es favorable, por tanto es importante hacer un

Técnico (T)

Administrativo

(A) inventario de los productos, enmiendas, agroquímicos y otras sustancias contaminantes que se estén utilizando. Esa facilidad de infiltración promovida por un suelo en su mayoría franco-arenoso, formado a base de cenizas volcánicas, deja abierta la posibilidad de que tanto sustancias químicas como excretas de animales alcancen a contaminar el agua subterránea. Un Plan de Monitoreo del agua utilizada para consumo humano, mediante la realización de análisis químicos y microbiológicos periódicos, puede ser testigo de esta probabilidad latente.

(VII) Inventariar y clasificar las prácticas de producción utilizadas en el área de estudio, ya sean estas favorables o no favorables a la infiltración. Ello permitirá identificar y promover cambios en la producción que facilite la recarga de aguas subterráneas.

(VIII) Aunque actualmente se cuenta con agua subterránea suficiente para satisfacer la demanda, a futuro esta situación dependerá del manejo que se le de a las ARH. Una manera de prever posibles reducciones en el nivel de agua subterránea es promover la inyección artificial de agua. Algunos de los métodos que podrían implementarse en el área de estudio son (Linsley et al. 1977):

a. Desviación del caudal de los ríos hacia áreas altamente permeables.

b. Excavación de fosas de precolación hasta penetrar áreas permeables.

c. Construcción de pozos adyacentes a un río para inducir precolación a partir del mismo.

d. Construcción de trampas que permitan el almacenamiento de agua en áreas de alta permeabilidad.

e. Construcción de acequias, diques o lagunas.

(IX) Realizar un estudio hidrogeológico que demuestre si existe o no acuífero en la zona. Ya conociendo las ARH, con este tipo de estudio de naturaleza subterránea se puede determinar la dirección del flujo y el almacenamiento del agua subterránea una vez que ésta percola. El conocer esta información permitirá ejercer un ordenamiento territorial congruente con los fines de protección y conservación del agua subterránea en la zona.

(I) Es fundamental el acercamiento amistoso y consiente que puedan tener y mantener las ASADAS y otras organizaciones o empresas con los productores de la zona. Conversatorios, charlas u exposiciones relacionadas con el tema hídrico, pueden llevar a un pensamiento común para ejercer acciones en vías de proteger las ARH y conservar el recuro hídrico subterráneo actualmente disponible. Algunas de esas acciones o alternativas consisten en realizar cambios en las técnicas de producción tradicional o inclusive definir y negociar pagos, compensaciones y hasta compra de terrenos, prioritariamente sobre aquellas áreas donde el volumen de recarga es importante.

(II) Tanto las ASADAS, hidroeléctrica El Embalse y otros actores locales, requieren del acompañamiento técnico y de los recursos económicos necesarios para implementar acciones con el fin de dar manejo adecuado a las ARH identificadas.

(III) Mantener actividades de capacitación y educación en relación con la proveniencia, importancia social y protección y conservación participativa que amerita el recurso hídrico subterráneo.

(IV) Las personas, instituciones y organizaciones implicadas en la protección y conservación del recurso hídrico, pueden ser parte de un plan de monitoreo y seguimiento que cuente con indicadores prácticos para medir el impacto que tienen las acciones de manejo implementadas.

(V) Los costos de protección y manejo de las $\mathrm{ARH}$, en buena parte pueden recaer sobre las personas directamente favorecidas con el recurso hídrico subterráneo en la zona. Las ASADAS locales, la empresa hidroeléctrica El Embalse, los productores y la misma población local, son los responsables de destinar un porcentaje de su presupuesto para la protección y mejoramiento de las ARH. Esa asignación y necesidad económica puede determinarse más acertadamente con la realización de un estudio de valoración económica del recurso hídrico.

(VI) Aprovechar la ubicación estratégica de las microcuencas Palo, Marín y San Rafaelito, como afluentes de la gran cuenca del río San Carlos, para la cual COOPELESCA financia e implementa un plan de rehabilitación y restauración. Además, en el año 2006 se ha designado al Área de Conservación Arenal Huetar Norte (ACAHN) como Reserva de la Biosfera "Agua y Paz", haciendo posible mediante la cooperación técnica, la coordinación y ejecución de acciones en el ámbito de la conservación del recurso hídrico. No hay que dejar de lado los esfuerzos que se lleven a cabo de manera integral a nivel local entre productores, ASADAS, Empresas Hidroeléctricas, Asociaciones de Desarrollo, Asociaciones Ambientalistas, MINAET, AyA y Municipalidad de San Carlos. 
Las pendientes y precipitaciones altas que predominan sobre el área de estudio, así como un suelo de origen volcánico que favorece la infiltración del agua en el suelo, llevan a suponer que el agua que tiene contacto en las $A R H$, puede tanto infiltrarse y ser retenida, percolar para recargar un posible acuífero profundo o correr subsuperficialmente para desembocar en manantiales estaciónales o cauces de ríos. En general, la velocidad del agua subsuperficial es muy baja y con un periodo largo de verano esta agua es la que en a primera instancia se ve afectada por la evapotranspiración. Es muy posible que los riachuelos y manantiales temporales o periódicos que se presentan dentro del área de estudio, sean parte de la descarga del agua subsuperficial en la zona (Faustino 2008). El hecho de contar con caudales en cauces y manantiales en época de verano, aun cuando no existen precipitaciones, es evidencia de que el área de estudio se encuentra sobre una importante captación de agua subterránea o acuífero.

Según investigaciones realizadas por Alvarado et al. (2001), la retención de humedad depende de la textura, la minerología y la estructura del suelo. Este autor menciona que los suelos volcánicos viejos pueden estar conformados hasta por un $70 \%$ de porosidad total, del cual un $38 \%$ corresponde a macroporos con un tamaño mayor a $30 \mu \mathrm{m}$ (micrómetros) y un $62 \%$ se refiere a microporos con diámetros menores a $30 \mu \mathrm{m}$. Por ser un suelo relativamente joven, es posible que el área de estudio no presente una porosidad total tan alta, pero se debe rescatar la posible presencia de un buen porcentaje de microporos, los cuales debido a las fuerzas capilares, provocan una mayor succión o atracción de agua y por lo tanto, generan una mayor posibilidad de retener humedad (Davie 2002). Para Bras (1990) la columna de agua en suelos con un mayor porcentaje de arcillas puede llegar a contener 10 veces más agua retenida que un suelo arenoso y Maidment (1993) menciona que es mayor la capacidad de retención en suelos con un contenido de arcilla mayor a $10 \%$, algo que caracteriza a los tipos de suelo presentes en el área de estudio. No obstante, no es despreciable la presencia de limo y arena, con valores entre $30 \%$ y $50 \%$ respectivamente, los cuales favorecen la percolación y recarga directa de un posible acuífero profundo en la zona (Ward \& Trimble 2004). También se debe tener presente lo mencionado por Duke (1974), quien afirma que, tanto en suelos arenosos como arcillosos, es posible que se dé un equilibrio de la tensión o presión ejercida sobre el agua, facilitando la retención de humedad. Por lo anterior, es posible mencionar que tanto la capacidad de retención como la de percolación, son las responsables de mantener los flujos de agua subterránea durante todo el año, siendo en términos de Rp, la percolación el fenómeno más importante ocurrido durante las precipitaciones y la retención de humedad dada cuando las precipitaciones no se presentan o son escasas.

Según la descripción geológica que realizan Arenas et al. (1997), dentro del área de estudio se encuentra un suelo relativamente joven, de origen ígneo o volcánico afectado por procesos erosivos, tectónicos y el vulcanismo dado en el Volcán Platanar en el periodo Cuaternario. En un suelo no consolidado de orden Andisol (Wiley 1959), el alto contenido de arenas debido a su origen ígneo (Alvarado et al. 2001), permite mayor espacio poroso que a su vez favorece la percolación de agua hacia capas más profundas del suelo, contribuyendo así con la recarga de aguas subterráneas. Este fenómeno ocurre en los tres tipos de suelo y es el que a pesar de las pendientes superiores a $7 \%$ que se presentan, pareciera contribuir con el hecho de que más de 23 millones de $\mathrm{m}^{3}$ de agua recarguen anualmente en las 25 ARH identificadas.

Los tres tipos de suelo identificados presentan capacidad para retener humedad debido a que cuentan con altos valores de capacidad de campo (CC) y bajos valores de densidad aparente ( $\rho a)$, dicho en otras palabras, los pequeños espacios porosos del suelo, hacen posible que un mayor volumen de agua se retenga en el suelo, favoreciendo así la recarga de aguas subterráneas. Ahora bien, específicamente el tipo de suelo 3 presenta una mayor capacidad de retención de humedad, en comparación con los tipos de suelo 1 y 2 , que presentan una capacidad menor, pero siempre importante en términos de recarga hídrica. Por su efecto "sombra-esponja", el bosque tiene mayor capacidad de regular la humedad y la temperatura del suelo, al provocar que éstas se den en proporciones más bajas que las que imperan en la atmósfera (Reynolds \& Thompson 1988). Así también, el bosque retarda la infiltración y almacena a largo plazo una mayor cantidad de humedad, por lo tanto, este tipo de cobertura, contribuye con la descarga de agua subterránea, aun en periodos donde no se dan precipitaciones. El tipo de suelo con mayor capacidad para retener humedad (suelo 3 ) en su mayoría se encuentra cubierto de bosque y es parte del Área Silvestre Protegida llamada Parque Nacional del Agua Juan Castro Blanco (PNAJCB). Los tipos de suelo 1 y 2 , también favorecen, aunque en menor medida, la infiltración y retención de humedad, el problema que se presenta en estas áreas, es que las altas pendientes y la compactación dada en la superficie del suelo cubierto por cultivos de caña, zacate y pastizal, provoca que los valores de infiltración básica (fc) sean menores, afectándose así, la capacidad de retención de humedad y percolación que presentan estos suelos (Jones 1997).

Con las pruebas de fc se obtiene una aproximación teórica de la capacidad de infiltración del suelo o su 
permeabilidad. El hecho de que los valores de fc sean mayores en suelos cubiertos por bosque, intermedios en el suelo cubierto con zacate $50 \%$ y $75 \%$ y menores en suelos cubiertos por pastizal y caña, reflejan la importancia de conservar el recurso boscoso de una manera intercalada en aquellas ARH donde éste no existe. La compactación, desintegración y erosión de las partículas del suelo, aunado a las altas pendientes que predominan en áreas cubiertas por zacate, pastizal y caña, ponen en riesgo lo mencionado por Ward \& Trimble (2004), quienes afirman que la textura fraco-arcillosa, el alto contenido de materia orgánica y la baja densidad aparente, induce a una alta capacidad de infiltración, haciendo a estos suelos de origen volcánico altamente permeables. Para Reynolds \& Thompson (1988), la capa de humus que se forma en la base del suelo de un bosque, protege a éste de la compactación causada por la lluvia, regula la humedad y el flujo pausado del agua, además, aporta materia orgánica al suelo y funciona como filtro al no permitir el paso de pequeñas partículas que pueden rellenar el espacio poroso. Estas atribuciones contribuyen a la justificación del porque en el bosque se da una mayor capacidad de infiltración.

Los resultados de precipitación que infiltra $(\mathrm{Pi})$ y de $\mathrm{Rp}$, muestran cómo influye la evapotranspiración real (ETR) en la estimación del volumen de agua que potencialmente puede llegar a ser parte del agua subterránea. La disponibilidad de agua para Rp está determinada en buena parte por el tamaño de la zona de raíces y el régimen climático. En los periodos largos sin Iluvia, la cobertura forestal de raíces profundas transpira libremente la mayor parte del tiempo aun cuando se haya terminado la disponibilidad de agua para plantas con raíces poco profundas. Esa condición se demuestra cuando los valores de ETR son mayores en bosques, zacate $50 \%$ y zacate $75 \%$. En áreas donde las plantas con raíces poco profundas como el pastizal y la caña reciben una adecuada cantidad de agua la mayor parte del tiempo, la evapotranspiración es afectada en menor grado por la profundidad de la zona de raíces (Linsley et al. 1977). Según Sánchez (2005), el proceso de la fotosíntesis es otro factor que influye en la evapotranspiración, a mayor intensidad de la luz solar, mayor intensidad de la fotosíntesis, con la cual se produce mayor cantidad de savia elaborada, quedando mayor cantidad de agua sobrante que induce una mayor transpiración. Además, la savia o glucosa se requiere en mayores cantidades en tipos de cobertura con mayor masa vegetal, este es el caso del bosque, zacate $50 \%$ y zacate $75 \%$. Todas las variables anteriores justifican el porqué en el área de estudio, un $50 \%$ de la Pi, sea ETR.

Aunque la fc sea mayor en bosque y menor en caña, zacates y pastizal, los resultados de $\mathrm{Rp}$ en todas las $\mathrm{ARH}$ tienden a ser moderadamente uniformes, con valores

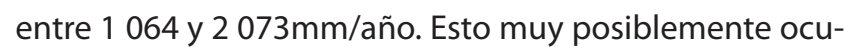
rre debido a que la ETR también es mayor en bosque y menor en caña, zacates y pastizal, ejerciendo cierto balance en la Rp (Ward \& Trimble 2004). Ahora bien, los valores de Rp se han obtenido en un momento y espacio dado y en realidad, es el cambio en las propiedades físicas del suelo, la erosión, la compactación del suelo y una mayor escorrentía, las que pueden provocar a futuro una disminución de la Rp, especialmente en aquellos suelos con una cobertura distinta a la boscosa. Según Wiley (1959), dada su importancia en la infiltración, la cobertura del suelo es más importante que el tipo de suelo existente, pues se han hecho estudios donde en un mismo suelo, distintos tipos de cobertura vegetal presentan diversas tasas de infiltración. Es por ello que, tanto el tipo de cobertura vegetal, como el manejo que se le dé, es un aspecto primordial en términos de favorecer la Rp a largo plazo.

Tanto el pastizal, el zacate y la caña son plantas perennes, pero su aprovechamiento se da mensual o anualmente, este hecho genera una mayor remoción y compactación del suelo, causada por la maquinaria y el ganado. Este efecto a través de los años puede provocar una disminución de la capacidad del suelo para infiltrar y retener agua, generando un aumento en los índices de escorrentía promovida por las altas pendientes que ocurren en toda el área de estudio. Aunque los resultados de Rp en las ARH que comparten estos tipos de cobertura actualmente son favorables, pueden no ser así cuando las lluvias merman y mucho menos cuando a través de los años se le siga dando un uso inadecuado a las mismas. Se conoce por ejemplo que la conversión de bosque tropical a pastizal, provoca un decrecimiento en el régimen de precipitación en alrededor de 200 mm/año, algo poco alentador si se sabe que en su mayoría, la recarga de aguas subterráneas proviene directamente de las precipitaciones (Reynolds \& Thompson 1988).

Aunque en el bosque se da una mayor ETR durante todo el año y especialmente en época de verano (Ward \& Trimble 2004), la capacidad de regulación y almacenamiento de humedad y la alta capacidad de infiltración que presentan los suelos cubiertos por bosque, provoca la percolación de casi un $65 \%$ del total del volumen de recarga hídrica. Paralelo a este aporte importante del bosque, Jones (1997) afirma que cuando un área forestal es reemplazada por pastizales o cultivos, es muy probable que en ese lugar se presente un aumento en la escorrentía superficial y una reducción considerable en las tasas de intercepción, evapotranspiración y capacidad de infiltración. Es importante considerar lo mencionado por Reynolds \& Thompson (1988), quienes mencionan que un cambio de cobertura del suelo a bosque, implica un incremento en la descarga de aguas subterráneas de al menos 450mm por 
año, igualmente, existen evidencias de que la cobertura forestal densa, implica un aumento de $5 \%$ en el régimen de precipitación anual.

En las ARH con categoría de recarga baja (un 20\% del área de estudio) deben darse a corto plazo, cambios en las técnicas de producción que permitan una mayor capacidad de retención y percolación que contribuya con la recarga de aguas subterráneas. En el restante $80 \%$ del territorio (del cual 54\% está cubierto por bosque) representado por ARH con categoría de recarga media y alta, las acciones de manejo deben avocarse a la protección y conservación, ello con el objetivo de mantener y aumentar los valores de recarga hídrica a un mediano y largo plazo. Para cada una de las ARH con baja, media o alta Rp, se sugieren acciones de manejo con el fin de alcanzar este fin.

Aunque por extensión, en la microcuenca Palo es donde se da el mayor porcentaje de Rp anual (62\%), tanto en ésta como en las microcuencas Marín y San Rafaelito, recargan en promedio $1,6 \mathrm{~m}^{3} / \mathrm{m}^{2}$ durante todo el año. Este valor, aunque importante, se presenta de manera poco uniforme, dándose mayor Rp en los meses que imperan las precipitaciones. Ante tal situación, la implementación de acciones de manejo en las ARH, busca aumentar este valor y lograr que éste ocurra de manera más uniforme a través de todo el año.

Según Matus (2007), la implementación de acciones de manejo con el fin de aumentar el volumen de descarga subterránea, es posible a corto plazo. Este autor es testigo de resultados obtenidos en fincas agrícolas donde acciones como la construcción de zanjas de infiltración, la siembra de barreras vivas, la rotación del cultivo y la siembra en curvas a nivel, en un periodo de cinco años, permitió aumentar el caudal de un manantial 5 veces en época de estiaje y 20 veces en época de invierno. Igualmente, Jones (1997), menciona que el solo hecho de reforestar un $10 \%$ de en una hectárea de pastizal, implica reducir la escorrentía en un $2 \%$. Sin duda estos resultados pueden brindar gran beneficio y podrían mitigar las constantes reducciones de caudal tanto en ríos como en manantiales de la zona. Esta información es un aliento para el trabajo y los resultados que puedan esperar las ASADAS locales, organizaciones ambientalistas y la hidroeléctrica El Embalse S.A.

Comparando los resultados de esta investigación, con los obtenidos por el Instituto de Políticas para la Sostenibilidad (IPS) en un balance hídrico realizado en el flanco noroeste del PNAJCB, resulta que los valores de Rp obtenidos, son muy congruentes con los resultados obtenidos por Barrantes \& Vega (2004), los cuales se presentan entre los 1400 y 2 500mm/año. Igualmente, en la presente investigación, la precipitación que infiltra es casi 14 veces mayor que la escorrentía y del agua precipitada, un $40 \%$ llega a ser parte de la recarga potencial de los acuíferos, algo muy similar ocurrido en el balance hídrico de Barrantes \& Vega (2004), donde este valor es de $36 \%$. Los más de 23 millones de $\mathrm{m}^{3}$ de agua que llegan a ser parte del agua subterránea cada año, son reflejo de los beneficios que se obtienen al presentarse en el área de estudio un grado de urbanización relativamente bajo (Aparicio 1989) y una influencia climática típica del bosque pluvial premontano (Salguero 2000). Es por eso que en general, tomando en cuenta la cantidad de variables geológicas y meteorológicas que se consideraron (Maidment 1993), la metodología aplicada y los resultados obtenidos en esta investigación, son bastante congruentes y apegados a la realidad.

Es evidente que el área de estudio recibe un importante volumen de precipitación anual, algo que es favorable en relación con la posibilidad de que esa agua precipitada, llegue a ser parte del agua subterránea. En el bosque que se encuentra en la parte alta de las microcuencas Palo, Marín y San Rafaelito, la vegetación en distintos estratos, así como el musgo y el mantillo, forman una especie de filtro que permite captar gran parte de las precipitaciones. Este efecto "retardador" del bosque provoca una disminución de la escorrentía y mayor oportunidad para que el agua infiltre hacia capas inferiores del suelo. Además, de los anteriores beneficios del bosque, hay que mencionar otros servicios potenciales como la conservación del suelo, fijación de dióxido de carbono $\left(\mathrm{CO}_{2}\right)$, conservación de la vida silvestre, materia prima para la industria maderera y artesanal, paisaje escénico natural y turismo sostenible, entre otros.

Aunque en el área de estudio existe una importante capacidad de infiltración y recarga de las aguas subterráneas, es claro que la ASADA de San Juan enfrenta reducciones de caudal importante en manantiales durante la época de verano, esto indica que, es la distribución estacional y muy marcada de las precipitaciones, la responsable de esta ocurrencia. Se debe tener presente entonces que las implicaciones del cambio climático mundial, pueden afectar la disponibilidad del flujo de agua subterránea en la zona y específicamente la capacidad de infiltración, retención y percolación directa del agua subterránea en época de invierno, es la que se debe aumentar si se quieren contrarrestar las reducciones de caudal en época de verano.

La parte media-alta de las tres microcuencas, es una importante área de captación y productora de agua. Este hecho, aunque positivo, no evita que el crecimiento poblacional, la condición climática estacional y el manejo inadecuado de las $\mathrm{ARH}$, provoquen la merma del nivel freático, reduciendo así, la capacidad de abastecimiento de agua potable. De las tres causas antes mencionadas, la de proteger 
y garantizar la existencia de ARH relevantes, es la que a nivel local y de una manera participativa, debe prevalecer.

La hipótesis de esta investigación es la siguiente: "En la parte media-alta de las microcuencas Palo, Marín y San Rafaelito no se identifican ARH que sean relevantes para su conservación". Esta hipótesis ha sido nula, pues los resultados obtenidos indican que sí existen ARH importantes, que deben ser mejoradas y conservadas con el fin mantener y aumentar la Rp a largo plazo.

\section{AGRADECIMIENTOS}

A Jorge Faustino, Arnulfo Días y Pablo Ramírez, quienes con tanto profesionalismo guiaron el desarrollo de esta investigación. Igualmente a la Junta Directiva de la Asociación Administradora de Acueducto Rural de San Juan (ASADA), por su interés y disposición a colaborar con el presente estudio.

\section{REFERENCIAS}

Alvarado, A. \& W. Forsythe. 2005. Variación de la densidad aparente en órdenes de suelos de Costa Rica. Revista Agronomía Costarricense 29:85-94.

Alvarado, A., F. Bertsch \& E. Bornemisza. 2001. Suelos derivados de cenizas volcánicas (Andisoles) de Costa Rica. Universidad de Costa Rica, San José, Costa Rica.

Aparicio, F. 1989. Fundamentos de hidrología de superficie. Limusa, México.

Arenas, A., S. Chaves \& P. Cordero. 1997. Diagnóstico del Parque Nacional Juan Castro Blanco: Estudio de las condiciones físicas generales de la zona de estudio. Universidad de Costa Rica, San José, Costa Rica.

Asamblea Legislativa. 2004. Ley de Aguas No. 276. 4a ed. IJSA, San José, Costa Rica.

Asamblea Legislativa. 1996. Ley Forestal No. 276. IJSA, San José, Costa Rica.

Barrantes, G. \& M. Vega. 2004. Estrategia para la Implementación del Servicio Ambiental Hídrico en el Parque Nacional del Agua Juan Castro Blanco (PNAJCB), Área de Conservación Arenal-Huetar Norte. Instituto de Políticas para la Sostenibilidad (IPS). San Carlos, Alajuela, Costa Rica.

Bras, R. 1990. Hydrology: An introduction to hydrologic science. Addison-Wesley, Massachussets, USA.

Calvo, R. 1996. Agua potable: Condición actual y perspectivas futuras en relación con las políticas institucionales. Universidad Nacional, Heredia, Costa Rica.

Centro Nacional de Alta Tecnología (CENAT). 2005. Foto Aérea Georeferenciada Encarta 2005 № 485p0351. CENAT, San José, Costa Rica.
Centro de Investigaciones Agronómicas (CIA). 2007. Laboratorio de recursos naturales de la Universidad de Costa Rica. UCR, San José, Costa Rica.

Custodio, E. \& M. Llamas. 1983. Hidrología subterránea. Omega, Barcelona, España.

Davie, T. 2002. Fundamentals of hydrology. Fundamentals of physical geography. Routledge, New York, USA.

Duke, J. 1974. Relaciones hídricas de suelo y planta. Edutex, México.

Faustino, J. 2008. Flujo de agua subterránea. CATIE, Cartago, Costa Rica. Comunicación personal.

Gómez, M. 2003. Elementos de estadística descriptiva. Universidad Estatal a Distancia, San José, Costa Rica.

Guzmán, E. 2004. Propuesta de manejo para el Parque Nacional del Agua Juan Castro Blanco. Tesis Profesional. Universidad Estatal a Distancia, San Carlos, Costa Rica.

Hernández, C. \& G. Cabalceta. 1999. Guía práctica para el estudio introductoria de los suelos con un enfoque agrícola. ACCS-UCR, San José, Costa Rica.

Instituto Geográfico Nacional (IGN). 1986. Hojas cartográficas georeferenciadas de Aguas Zarcas ( No 3347 III) y Quesada (№ 3346 IV). Escala 1: 50.000. San José, Costa Rica.

Instituto Meteorológico Nacional (IMN). 2007. Información meteorológica. Base de datos de precipitación y temperatura para la zona norte de Costa Rica.

Instituto Costarricense de Electricidad (ICE). 2007. Información meteorológica. Base de datos de precipitación referentes a las estaciones meteorológicas ubicadas para interés de los proyectos hidroeléctricos Toro.

Instituto Costarricense de Acueductos y Alcantarillados (AyA). 2004. Actualización del plan estratégico 2003 al 2020. Acuerdo $N^{\circ}$ 2005-944.

Instituto Tecnológico de Costa Rica (ITCR). 2004. Atlas digital de Costa Rica.

Jones, J. 1997. Global hydrology. processes, resources and environmental management. Longman, London, Inglaterra.

Maidment, D. 1993. Handbook of hidrology. Infiltration and soil water movement. McGraw-Hill, New York, USA.

Matus, O. 2007. Elaboración participativa de una metodología para la identificación de áreas potenciales de recarga hídrica en subcuencas hidrográficas, aplicada a la subcuenca del río Jucuapa, Matagalpa, Nicaragua. Tesis Profesional. CATIE, Turrialba, Costa Rica.

Ministerio de Agricultura y Ganadería (MAG). 2000. Estudio de suelos y capacidad de uso de las tierras para la zonificación agropecuaria de las regiones Huetar Atlántica, Huetar Norte y Brunca, MIDEPLAN, San José, Costa Rica.

Laporte G. 1994. Reconocimiento geológico del proyecto hidroeléctrico "El Embalse". Ciudad Quesada, San Carlos, Costa Rica. 
Linsley, M., M. Kohler \& J. Paulhus. 1977. Hidrología para ingenieros. McGraw-Hill, México.

Ochoa, L. 2007. Información general de la Asociación Administrativa del Acueducto Rural de San Juan (entrevista no estructurada). Alajuela, Costa Rica. Comunicación personal.

Orozco, E., T. Padilla \& M. Salguero. 2003. Manual técnico: Metodología para la determinación de áreas de recarga hídrica natural (ARHN).

Reynolds, E. \& F. Thompson. 1988. Forest, climate and hydrology: regional impacts. United Nations University, Tokyo, Japon.

Sánchez, J. 2005. La evapotranspiración. Universidad de Salamanca, España.
Salguero, M. 2000. Cantones de Costa Rica. Costa Rica, San José, Costa Rica.

Schosinsky, G. 2006. Calculo de la recarga potencial de acuíferos mediante un balance hídrico de suelos. Revista Geológica de América Central 34-35:13-30.

Villón, M. 2004. Hidrología. Instituto Tecnológico de Costa Rica, Cartago, Costa Rica.

Ward, A. \& S. Trimble. 2004. Environmental hydrology. CRC, Washington, USA.

Wiley, J. 1959. Hydrology. Infiltration and soil moisture. CRC, New York, USA. 